\title{
Cis-clustering of cadherin-23 controls the kinetics of cell-cell adhesion
}

\section{Cheerneni S Srinivas", Gayathri S Singaraju", Sayan Das, Amin Sagar¹, Anuj Kumar², and Sabyasachi Rakshit ${ }^{1,3 *}$}

${ }^{1}$ Department of Chemical Sciences, Indian Institute of Science Education and Research Mohali, Punjab, India.

${ }^{2}$ Department of Physical Sciences, Indian Institute of Science Education and Research Mohali, Punjab, India.

${ }^{3}$ Centre for Protein Science Design and Engineering, Indian Institute of Science Education and Research Mohali, Punjab, India.

*Correspondence to Sabyasachi Rakshit

Email: srakshit@iisermohali.ac.in

${ }^{\#}$ Equal contributions

\begin{abstract}
Cis and trans-interactions in cadherins are the foundations of multicellularity. While the transinteraction mediate cell-cell adhesion, the cis-interaction is postulated as strengthening to trans by clustering. The well-accepted model in cadherin-adhesion is that the 'trans precedes cis' via a diffusion-trap kinetic model. Here we report that cadherin-23, a non-classical cadherin with an extended extracellular region, undergoes clustering in solution via lateral interactions independent of trans and phase separate as liquid droplets. In cellulo using fluorescence-recovery after the photobleaching, we noticed a significantly slow-diffusion of cadherin-23 at the intercellular junctions, indicating the diffusion of a cluster. The cis-clustering accelerates the cell-cell adhesion and, thus, kinetically controls cell-adhesion via 'cis precedes trans' model. Though the connection of cis-clustering with the rapid adhesion is yet to explore, M2-macrophages that predominantly express cadherin-23 undergo fast attachments to circulatory tumor cells during metastasis.
\end{abstract}

\section{Introduction}

Cadherins predominantly maneuver the active cell-adhesion processes for both vertebrates and invertebrates. Two modes of binding are known for cadherins, trans-binding and cis-binding. While in trans-binding, the terminal extracellular (EC) domains of cadherins from opponent cells interact, the cis-binding is mediated by the lateral interactions among the rest of the EC domains of cadherins from the same cell surfaces(Harrison et al., 2011). Trans mediates direct contacts among opposing cells via a diffusion-trap kinetic approach and secures a cell-cell junction. For classical E(pithelial)-cadherins, approximately five independent protein molecules, clustered at the 
intracellular region by the cortical F-actin filaments, diffuse across the membrane and are trapped via trans-interactions with E-cadherins of neighboring cells and initiate the cell-cell adherin junctions (Wu et al., 2015). Lateral interactions, thereafter, influence the clustering of cadherins on the premature junctions and strengthen the association between cells. Cis-interaction is thus conceptually referred to as reinforcement to the trans-mediated cellular junctions for classical cadherins. However, this need not be universally true for all cadherins.

A sizeable conformational entropy and homotypic protein-protein repulsions against weak cisinteractions have been the limitations for cis clustering in solution. Results from molecular dynamics and Monte-Carlo simulations conceptualized the two-dimensional confinement of proteins as a solution to reduce the conformational entropy and neutralization of protein-protein repulsions, favoring independent cis clusters for classical cadherins. This is experimentally verified with E-cadherins on a supported lipid bilayer and monitored using single-particle tracking and FRET(Thompson et al., 2019, Thompson et al., 2020). However, capturing cadherin clusters mediated predominantly by cis-interactions in traditional solution-phase assays and studying their functional relevance has still been elusive yet demanding.

Clustering of solute in a solution is a classical phase separation to condensed phase from the dilute phase. In cell biology, such a liquid-liquid phase separation (LLPS) is common in the cytoplasm. It is the developmental origin of the membrane-less liquid compartments like nucleoli(Latonen, 2019), centrosomes(Mahen and Venkitaraman, 2012), Cajal bodies(Gall, 2003), stress granules(Buchan and Parker, 2009). Relatively uncommon, but the existence of LLPS is also reported with proteins like Zonula Occludens (Beutel et al., 2019), nephrin(Banjade and Rosen, 2014) that are anchored to cell-membrane and mediate multiprotein cell-adhesion, signal transduction. Favorable interactions among like-neighbors are thermodynamically responsible for such phase separations. Such favorable interactions are also present in cadherins and drive cisclustering on two-dimensional confinement; however, the conformational entropy and proteinprotein repulsion often overpower the cis-clustering in solution. Intuitively, controlled tuning of the counterbalancing interactions may favour the clustering and subsequently, the LLPS with cadherins.

We performed an unbiased in silico search using the catGRANULE algorithm(Mitchell et al., 2013, Klus et al., 2014) across the cadherin-superfamily of proteins and identified cadherin-23 (Cdh23) (NP_075859) protein with a high propensity to undergo LLPS. Cdh23 is one of the long non-classical classes of cadherins with 27 extracellular domains. It mediates strong cell-cell adhesion among tissues like the heart, kidney, muscle, and testis homophilically(Sannigrahi et al., 2019, Singaraju et al., 2019, Sotomayor et al., 2012), and heterophilic interactions with protocadherin-15 in neuroepithelial cells(Sotomayor et al., 2010). Interestingly, with the potential for multivalent lateral interactions, Cdh23 engages in a stable spiral cis-dimerization(Kachar et al., 2000). The cis-interactions of Cdh23 facilitate clustering and phase separation to liquid droplets in solution. The phenomenon is critical to the ionic strength of the buffer. We quantitatively derived the relation of cis-clustering mediated LLPS of Cdh23.

To confirm the contribution of cis-interactions in LLPS, we specifically blocked the transinteractions of $\operatorname{Cdh} 23$ and measured the extent of LLPS. Further, we used chemical needles like 
1,6-Hexanediol (HD) that rupture liquid droplets of biomacromolecules by non-specifically blocking interparticle interactions (Patel et al., 2017). We noticed no LLPS of Cdh23 in-vitro after 1,6-HD treatment. Free-standing cis-clustering of $\mathrm{Cdh} 23$ independent of trans-binding prompted us to study the effect on cell adhesion. We measured a significant acceleration in the rate of cellcell adhesions driven by cis-clustering. We noticed a substantial drop in cell-adhesion kinetics upon disruption of cis-clusters by 1,6-HD, supporting the functional implication of cis-clustering in cell-cell adhesion. Notably, while the toxicity of the phase-separated states has already been proposed for intrinsically disordered proteins(Elbaum-Garfinkle, 2019), the fast-aggregation of cells is a demonstration of the functional implication of LLPS in cell adhesion. Our fluorescence recovery after photobleaching (FRAP) experiments revealed the fluidic nature of the Cdh23clusters at the cell-cell junctions.

\section{Results}

\section{Cdh23 with 27 EC domains undergoes LLPS}

The presence of $\mathrm{Ca}^{2+}$ ions in the coordination sphere of cadherins reduces conformational variations. Further, inert polymers like polyethylene glycol (PEG) molecules often occupy the excluded protein volume and reduce protein entropy(Kaur et al., 2019, Delarue et al., 2018). Besides, Cdh23 EC1-27 has 440 negatively charged and 222 positively charged amino acid residues distributed throughout its structure, thus possessing coacervation propensity. It is, therefore, an interplay between the concentration of $\mathrm{Ca}^{2+}$ ions, ionic strength of the buffer, and the protein proximity optimizes the lateral interactions in $\mathrm{Cdh} 23$ and drive phase separation in solution. Our in-silico search identified the EC regions in Cdh23 as more prone towards phase separation with a propensity score of 1.3. Usually, a propensity score higher than 1 is considered a good LLPS candidate(Ambadipudi et al., 2017). However, the propensity score for Cdh23 EC110, a truncated isoform, was measured lower than 1 (Fig. S1). Inference from the crystallographic studies has also revealed that EC domains 14, 17, 20, 21, 23, and 25 are predominantly responsible for cis-interactions in Cdh23(Jaiganesh et al., 2018). To verify, we designed two variants of Cdh23: Cdh23 EC1-27, a variant with an entire EC region, thus possessing high-propensity for LLPS, and a truncated version, Cdh23 EC1-10, with a low-propensity for LLPS. Reportedly, Cdh23, apart from cis-interactions, can mediate both homophilic and heterophilic transinteractions. Two types of trans-interactions with two distinct binding affinities were reported between Cdh23 and Pcdh15 (Narui and Sotomayor, 2018). The most robust trans-conformation with a dissociation constant of $<1 \mu \mathrm{M}$ was notified for the canonical variant. The second transconformation with a higher dissociation constant of $5 \mu \mathrm{M}$, was observed for a truncated variant. It was, therefore, necessary to block the interference of the trans-interactions to measure the strength of cis-binding. Notably, the heterophilic trans-interaction with Pcdh15 has the highest affinity (Table 1) (Choudhary et al., 2020, Singaraju et al., 2019, Sotomayor et al., 2012).

To corroborate our in-silico observations on clustering propensity of $\mathrm{Cdh} 23$ EC1-27, we systematically varied the protein concentrations and the ionic strength of the buffer and checked the cis-clustering in solution. We recombinantly tagged eGFP at the C-terminal of each variant to 
visually track the cis-induced phase separations in real-time under a fluorescence microscope. 20 $\mathrm{mM}$ of HEPES buffer at $\mathrm{pH} 7.5$ was used for all experiments, and $0.5 \%$ of PEG6000 was used as a crowding agent. We noticed the condensates of $\mathrm{Cdh} 23 \mathrm{EC} 1-27$ proteins for a range of protein concentrations, ionic strengths, and $\mathrm{Ca}^{2+}$ concentrations (Fig. $1 \mathrm{~A}, \mathrm{~B}$ and $\mathrm{C}$ ). Association of the green fluorescence with the protein confirmed that the condensates are made of Cdh23 (Fig. $1 \mathrm{~B}$ and Video $1 \mathrm{~A}$ ). Fusion among floating droplets, the gold standard for liquid condensates, is also noticed among Cdh23 condensates, indicating the fluid nature of the droplets (Fig. $1 \mathrm{~A}$ and Video $1 \mathrm{~B})$. Further from the time-trace analysis of the fusion events, we measured an average fusiontime of $5.0 \pm 1.2 \mathrm{~s}$, in range with other proteins that undergo LLPS (Wang et al., 2019) (Fig. S2 and Video $1 \mathrm{~B})$.

Attributing to the Hofmeister series, a standard theory to estimate protein stability and solubility, we systematically varied $\mathrm{Na}^{+} \& \mathrm{Ca}^{2+}$ ions to identify optimal conditions for the liquid-phase condensation of Cdh23 EC1-27(Dignon et al., 2020). The rate of droplet growth was monitored for optimization (Fig. 1 C). Towards this, we first varied $\mathrm{Na}^{+}$ions keeping $\mathrm{Ca}^{2+}$ ions fixed at 4 $\mathrm{mM}$. We noticed a gradual increase in droplet growth rate with increasing $\mathrm{Na}^{+}$ions, reaching an optimum at $500 \mathrm{mM}$ (Fig. 1 C). The phase separation of Cdh23 EC1-27 was noticed for $100 \mathrm{mM}$ $-1 \mathrm{M}$ of $\mathrm{NaCl}$. Next, we set the $\mathrm{Na}^{+}$ions to $500 \mathrm{mM}$ and altered $\mathrm{Ca}^{2+}$ ions, and obtained phase separation for a range of $4 \mathrm{mM}-10 \mathrm{mM}$ of $\mathrm{CaCl}_{2}$, and optimal at $6 \mathrm{mM}$ of $\mathrm{Ca}^{2+}$ (Fig. S3 A). Finally, we fixed the $\mathrm{Ca}^{2+}$ ions to $6 \mathrm{mM}$ and varied both [protein] and $\left[\mathrm{Na}^{+}\right]$ions to obtain a complete phase separation diagram (Fig. 1 D). The optimal growth rate of liquid droplets was obtained at $14 \mu \mathrm{M}$ of proteins, $535 \mathrm{mM}$ ionic strength, and $6 \mathrm{mM}$ of $\mathrm{Ca}^{2+}$ ions (Fig. $1 \mathrm{C}$ and D and Fig. S3 B and Fig. S4). We noted a lower critical concentration of 2.5 $\mu \mathrm{M}$ for Cdh23 EC1-27 for in vitro cis-clustering (Fig. $1 \mathrm{D}$ ). Also, $\mathrm{Na}^{+}$and $\mathrm{Ca}^{2+}$ ions beyond the salting-out range showed no LLPS for Cdh23 EC1-27. It is important to note that the optimal $\mathrm{Ca}^{2+}$ ions for in vitro LLPS of Cdh23 EC1-27 are within the scope of the extracellular region in physiology.

Interestingly, Cdh23 EC1-10 did not undergo phase separation for a wide range of buffer conditions, including the requirements maintained for $\mathrm{Cdh} 23 \mathrm{EC} 1-27$. We, therefore, considered the truncated version as the negative control. The point to note here is that both Cdh23 EC1-10 and Cdh23 EC1-27 have eGFP tags at their C-termini, and yet, Cdh23 EC1-27 is the only construct undergoing LLPS thus, withholding the contribution of eGFP in LLPS.

To validate the LLPS of Cdh23 EC1-27 as a resultant of exclusive cis-clustering, we repeated the phase transition experiment in the optimal condition, but by blocking the trans-interacting sites with ligand-protein, Pcdh15 EC1-2. As a precaution, we first facilitated the heterophilic transinteractions with an abundance of Pcdh15 EC1-2 (20 $\mu \mathrm{M})$ in the experiment buffer and carefully altered the solution's ionic strength from an unfavorable phase separation condition to a favorable state via dialysis (Materials and Methods). We observed LLPS of Cdh23 EC1-27 and Pcdh15 EC12 complex, indicating that the droplets are predominantly due to lateral interactions of Cdh23 (Fig. S5). Notably, the droplets of Cdh23 EC1-27 without Pcdh15 EC1-2 were more extensive than in Pcdh15 EC1-2, indicating that the additional trans-interactions contribute to the phase separation 
in vitro but are not essential for the LLPS. Overall, Cdh23 EC1-27 undergoes LLPS under physiological conditions, and the liquid droplets follow the characteristic feature of protein condensates.

\section{LLPS helps in faster cell-cell aggregation}

Liquid droplets of Cdh23 are not exclusive to in-vitro conditions. We observed mesoscopic liquidlike assemblies of Cdh23 in-cellulo in HEK293 cells stably expressing full-length Cdh23. Fulllength $\mathrm{Cdh} 23$, similar to the other cadherin family members, comprises a transmembrane domain and a cytosolic domain along with EC regions. Punctate structures in the mesoscopic to the microscopic regime were noticed at the cell-cell junctions of stably transfected HEK293 cells (Materials and Methods). The puncta structures were absent in control for immunofluorescence images, where only a secondary antibody was used for staining the cells (Fig. 2 A). Cellular droplets in cytosol separate homogeneous biomolecules into two phases, a condensed liquid droplet of specific biomolecules surrounded by a diluted phase. Since the foundation of the condensed phase is transient and weak intermolecular interactions, the liquid phase rapidly and reversibly undergoes de-mixing in response to chemical and physical cues, either triggered by incellulo activities or externally. 1,6-hexanediol (1,6- HD) is a widely used aliphatic alcohol in cell biology that weakens the hydrophobic interactions critical for LLPS and inhibits the condensation of solutes to liquid droplets(Itoh et al., 2021, Duster et al., 2021). Accordingly, we treated the stable HEK293 cells with 1,6-hexanediol and monitored the disruption of puncta structures, confirming the fluid nature of the Cdh23 clusters in cells (Fig. 2 A). Even in vitro, we noticed a complete demolishing of the condensed liquid phase in 1,6-HD (Fig. S6).

How do the liquid droplets of Cdh23 mediated by cis-clustering contribute to cells? Cadherins generally form anchoring junctions with the neighboring cells. Cdh23 is no different from the other family members and mediates vital cell-cell adhesion junctions in several tissues like the kidney, muscle, testes, and heart (Singaraju et al., 2019, Sannigrahi et al., 2019, Sotomayor et al., 2012, Li et al., 2019). We, therefore, verified the effect of the liquid condensates of Cdh23 mediated by cisclustering in cell-cell adhesion, more importantly where cis-clustering precedes the transinteractions. We hypothesized that cis-clustering on a membrane would increase the effective intercellular interacting interface and accelerate cell-adhesion kinetics. We thus monitored the aggregation-kinetics of HEK293 cells exogenously expressing Cdh23 and fit the kinetics data to Von Bertalanffy model (West and Newton, 2019, Benzekry et al., 2014) to estimate the relative adhesion-rate constants (Materials and Methods). We used the same two recombinant variants, Cdh23 EC1-27, and Cdh23 EC1-10, but along with the transmembrane (TM) and cytosolic domains (CD) at their C-terminals (NP_075859). For monitoring the localization of proteins on cell junctions, we fused eGFP at the extreme C-terminals of the constructs. We transfected these chimeric constructs in HEK293 cells, where the cells were pre-treated with siRNA to silence the endogenous Cdh23 expression precisely (Materials and Methods). As expected, we observed a significant enhancement in the aggregation-kinetics of cells expressing Cdh23 EC1-27 (rate constant, $a_{o n}^{0}=2.1 \times 10^{-3} \mathrm{~min}^{-1}$ ) (Fig. $2 \mathrm{~B}$ ) than the cells overexpressing Cdh23 EC1- 
$10\left(a_{o n}^{0}=3.4 \times 10^{-4} \mathrm{~min}^{-1}\right)($ Fig. $2 \mathrm{C})$. Important to note that both types of cells formed Cdh23 mediated matured cell-cell junction after incubation, warranting the functional activity of both constructs. HEK293 cells treated with siRNA for endogenous Cdh23 showed no aggregation within the experiment time.

Does cis-clustering on cell membrane depend on the extent of surface coverage by Cdh23? To check, we monitored the cell-aggregation kinetics among cancer cell lines, HEK293, HeLa, $\mathrm{HaCaT}$, and A549, that express endogenous Cdh23 differentially. Our results from qRT-PCR and western blot, in corroboration with TCGA, indicate higher endogenous expression of Cdh23 in A549, HaCaT cells and comparatively lower expression in HEK293, HeLa cell-lines (Fig. S7 A). Amongst all in the list, HeLa has the least expression. We performed the cell-aggregation assays in the previously optimized buffer condition and noticed significantly faster cell-aggregations for A549 and HaCat, than the low-expressing cell lines (HEK293 and HeLa). HeLa did not aggregate within the experiment time (Fig. $3 \mathrm{~A}$ and B). To conclude the differences in aggregation kinetics based on the extent of the cis-clustering, we performed the aggregation kinetics of A549 and HEK293 cells in the presence of 1,6-HD. The aggregation kinetics of both cells dropped significantly in the presence of 1,6-HD (Fig. 4 A and B) and became comparable among each other. Overall, the kinetic data w/o 1,6-HD indicate that the differences in cell-adhesion kinetics of A549 and HEK293 cells without 1,6-HD are due to differences in the extent of cis-clustering of $\mathrm{Cdh} 23$. When chemical treatments abolish the cis-clustering, the individual Cdh23 molecules on the cell membrane follow the trans-mediated diffusion-trap kinetics for cell adhesion, similar to classical cadherins. While cis-clustering increases the effective binding interface on a cell membrane and kinetically facilitates the cell adhesion, the diffusion trap is instead driven by the binding affinities between partners and, thus, independent of the surface coverage.

\section{Fluidic nature of $\mathrm{Cdh} 23$ clusters on the cell membrane}

Fluorescence recovery after photobleaching (FRAP) has been a valuable tool to decipher the fluidic nature of liquid droplets in in-vitro and in-cellulo conditions (Pincet et al., 2016, Kanaan et al., 2020). Accordingly, we performed FRAP experiments on the intercellular junctions of HEK293 cells that are stably transfected with $\mathrm{Cdh} 23$. The protein was recombinantly tagged with eGFP at the C-terminal. We noticed localization of eGFP at the cell-cell junctions as expected for Cdh23 (Fig. 5 A) and photobleached a confocal volume. Next, we monitored the fluorescence recovery along a line across the photobleaching spot (Fig. $5 \mathrm{~B}$ and $\mathrm{C}$ ). This is to identify if the recovery is from the new Cdh23 exported and recruited to the membrane by cells or diffusion of membrane-bound proteins. The fluorescence intensity profile across the line is expected to follow an inverted Gaussian profile with a deep at the center of the photobleaching spot (Fig. 5 D). We noticed widening in the Gaussian profiles with recovery, characteristics of diffusion of active proteins from the surrounding membrane. Recruitment of new proteins, in general, recover the fluorescence intensity without diluting the surroundings, thus with a little widening of the Gaussian width (Erami et al., 2016). Next, we plotted the width of the Gaussian $\left(\sigma^{2}\right)$ with time-lapsed after photobleaching and fit to the linear equation and estimated the diffusion-coefficient of Cdh23 
clusters at the cell-cell junctions (Fig. 5 E) (Materials and Methods). The diffusion-coefficient of Cdh23 clusters at the cell-cell junctions is $0.6 \times 10^{-3} \pm 0.1 \times 10^{-3} \mu \mathrm{m}^{2} \mathrm{~s}^{-1}, 8$-fold slower than the reported diffusion-coefficient of classical E-cadherin $\left(D_{\text {eff }}=4.8 \times 10^{-3} \pm 0.3 \times 10^{-3} \mu \mathrm{m}^{2} \mathrm{~s}^{-1}\right)$ clusters of 1000 molecules (Erami et al., 2016). Overall, our FRAP data indicates that Cdh23 at the cellcell junction is fluidic and diffuse in clusters.

\section{Discussion}

Cdh23 can condensate to the punctate liquid phase at the cell membrane and, as super-adhesive, rapidly seizes the floating cells into aggregates. Though dense, short-range punctate junctions are widely noted for the cadherin family of proteins, the physiological implication of rapid cell-cell adhesion/communication is still elusive. Here, we deciphered that the punctate could be liquid droplets of cadherins. Though, in the family of cadherins, this is the first report to highlight the ability of the cadherin proteins to undergo LLPS. The LLPS mediated faster cell-cell adhesion is also the first demonstration of the physiological implication of LLPS on the membrane. Cdh23, among other cadherins, is significantly overexpressed in tumor-infiltrating M2-type macrophages(Poczobutt et al., 2016) and microglia(Zhang et al., 2016, Zhang et al., 2014) (Fig. S7 B). M2-type macrophages associate with the circulatory tumor cells (CTCs) on the go and help in metastasis. A quick cell-cell adhesion is thus essential in this process. Though speculative, the fast adhesion between M2 macrophages and CTCs is facilitated by the condensed Cdh23 droplets.

Usually, weak multimodal interactions are among the driving forces for LLPS. The ectodomains of $\mathrm{Cdh} 23$ possess such multiple interaction sites, witnessed from the previously reported puckered and extended coil conformation of Cdh23 cis-dimer (Jaiganesh et al., 2018, Di Palma et al., 2001). The specific cis-interacting sites beyond the ectodomain number of 10 (dom10) were also identified from the fragmented crystal structures of Cdh23 domains(Jaiganesh et al., 2018). Further, the catGRANULE algorithm that predicts the LLPS propensity of a protein from the primary structure identified several granules forming sites on the ectodomains of Cdh23, majorly beyond dom10. Accordingly, we observed LLPS for Cdh23 EC1-27 at the lowest concentration of $2.5 \mu \mathrm{M}$ in vitro but no condensed liquid-like phase for Cdh23 EC1-10 even at a very high concentration of $100 \mu \mathrm{M}$. Our in-cellulo experiments also featured multifold faster rates $\left(a_{o n}^{0}\right)$ of cellular aggregation for cell-lines expressing full-length Cdh23 (Cdh23 EC1-27+TM+CD) $\left(a_{o n}^{0}=2.14 \times 10^{-3} \mathrm{~min}^{-1}\right)$ than the truncated form of Cdh23 (Cdh23 EC1-10+TM+CD) $\left(a_{o n}^{0}=\right.$ $\left.3.4 \times 10^{-4} \mathrm{~min}^{-1}\right)$. Together, our data indicate that the EC domains beyond 10 (EC10 - 27) is the key for LLPS. Data from FRAP experiments indicate that even at the cell-cell junctions, Cdh23 translocates as cis-clusters. Though we could not quantify the cluster size accurately, from the comparisons of the diffusion-coefficients, we noted approximately 8-fold mass-equivalence of $\mathrm{Cdh} 23$ clusters than the classical E-cadherins. It must be noted that the comparisons cannot be quantitative as cell lines under study are different.

The cis-dimerization of classical cadherins is generally considered the aftereffect of intercellular trans-interactions(Pontani et al., 2016). The physiological role of the cis-dimer is proposed to strengthen the trans-interactions at the cell-cell junction( $\mathrm{Wu}$ et al., 2010). The liquid phase condensate of Cdh23 on-membrane instead contributes to the kinetics of cell-cell adhesion. It 
drives the adhesion kinetics via the induced-fit model than the diffusion-trap as reported for classical cadherins. The adhesion kinetics is also dependent on the extent of surface coverage of $\mathrm{Cdh} 23$, so as the extent of cis-clustering. Interestingly, the extent of cis-clustering only affect the rate of cell-cell adhesion at the initial phase, and not the mature cell-cell junction. However, the physiological implication of such fast-snapping is still not well-understood.

Moreover, Cdh23 may not be the only cadherin in the family that can undergo LLPS. The Catgranule algorithm estimated the CDF score of more than 1 for many other cadherins (Table 2), considering only the ectodomains. In general, with a CDF of more than 1, the proteins show a tendency for LLPS. Accordingly, Fat-cadherin, Dacshous-cadherin, desmosomes, cadherin-22 have CDF scores of more than 1, and can undergo LLPS. Interestingly, most of these cadherins are associated with special cell-cell junctions. For instance, fat-cadherin and dacshous cadherinmediated heterophilic junctions exclusively regulate the epithelial cell-size dynamics (ECD) under the mechanical cues during morphogenesis (Kumar et al., 2020), desmoglein-2 forms heterophilic interactions with other isoforms of desmosomal cadherins and form $\mathrm{Ca}^{2+}$-independent hyperadhesive desmosomal junctions in tissues like skin, heart that are exposed to physical forces. Apart from cadherins, ZO1 that form tight-junctions (McNeil et al., 2006) also has a CDF score of more than 1 and undergoes LLPS (Beutel et al., 2019).

\section{Conclusion}

The distinctive features of liquid droplets, stretchable and tunable to different sizes and shapes, may be helpful in cell-cell junction, which routinely experiences mechanical assault. Our results address a functional feature that liquid condensates can achieve, but the individual functional counterparts cannot. Identifying the physiological or pathological cues that trigger such phase transitions is the next exciting step and may open up another exciting field of rapid cell-cell communication and adhesion.

\section{Materials and Methods}

\section{Cloning of domain deletion mutants of $\mathrm{Cdh} 23$}

The full-length Cdh23(NP_075859) consisting of 27 EC domains, a transmembrane domain, and a cytoplasmic domain was a generous gift from Dr. Raj Ladher, NCBS, Bangalore. Using this construct, we recombinantly generated domain deletion mutants. We have subcloned the same construct in pcDNA3.1 (+) plasmid, which code for Neomycin resistance. All the constructs were cloned between NheI and XhoI restriction sites with (S)-Sortase-tag (LPETGG)-(G)-eGFP-tag and (H)-His-tag; SGH-tag at downstream (C-terminus of the protein) in the same order. All the recombinant constructs were verified through double digestion, PCR amplification, and DNA sequencing.

\section{Protein expression and purification}

All recombinant Cdh23 variants for in-vitro studies were expressed in the ExpiCHO suspension cell system (A29129 ThermoFisher Scientific), following the prescribed protocol for transfection in ExpiCHO cells. After seven days, the culture media was collected by pelleting down the cells at $2000 \mathrm{rpm}$ for $15 \mathrm{~min}$ at room temperature. The media was then extensively dialyzed against the 
dialysis buffer for 48 hours and intermittently changed the buffer every 8 hours. The dialyzed media with proteins were purified using affinity chromatography using Ni-NTA columns. The purity of the samples was checked using SDS-PAGE. Finally, the presence of protein was confirmed using western blotting with specific antibodies against GFP, Cadherin-23, and his-tag.

\section{In vitro droplet formation assay}

All purified proteins were prepared in buffer containing $20 \mathrm{mM}$ HEPES, $\mathrm{pH} 7.5,100 \mathrm{mM} \mathrm{NaCl}$, $4 \mathrm{mM} \mathrm{CaCl}_{2}$. Before each experiment, the proteins were centrifuged at $15000 \mathrm{rpm}$ at $4^{\circ} \mathrm{C}$ for $10 \mathrm{~min}$ to remove possible nonspecific aggregates. Then proteins were adjusted to reach designated concentrations. Each protein mixture (14 $\mu \mathrm{M}$ for each component) was injected into a homemade chamber and imaged using a Leica microscope (Leica DMi8) using 40X objective lens. The time-lapse images were taken under bright-field and fluorescence filters. All the assayed droplets were thicker than $6 \mu \mathrm{m}$ in height, so the central layers of optical sections were chosen for quantification. Over 10 or more droplets were measured for each protein to generate the phase diagram of the condensed phase. The images were analyzed by ImageJ, and the quantification was performed by Origin software.

\section{Immunofluorescence and LLPS disruption studies}

Immunofluorescence staining was performed using Cadherin-23 (HPA017232, Sigma-Aldrich) primary antibody and Anti Rabbit IGG CF633 (SAB4600141, Sigma-Aldrich) secondary antibody. DAPI (Sigma-Aldrich) was used to stain the nuclei of the cells. Images of immunofluorescent labeled cells were obtained on a confocal microscope (Leica, TCS SP8) using a $63 \mathrm{X}$ objective lens. To disrupt the liquid-like clusters, Cdh23 stable HEK293 cells were incubated with 2\% (w/v) of 1,6-Hexanediol (H11807, Sigma-Aldrich) for 1 hour. Similarly, 10\% (w/v) of 1,6-Hexanediol was used to disrupt the liquid droplets of Cdh23 EC1-27 in-vitro.

\section{Western blot and qRT-PCR}

The adherent cancer cell lines HeLa, HEK293, A549, and HaCat were obtained from NCCS, Pune. All cells were cultured in high glucose DMEM media (D1152, Sigma-Aldrich) containing 10\% FBS and $5 \% \mathrm{CO}_{2}$. We followed the standard protocol(Hirano, 2012) for the western blotting of the lysates from the mentioned cell lines. Cadherin-23 (HPA017232, Sigma-Aldrich and PA543398, Invitrogen), eGFP (A11122, Invitrogen) and His-tag (11965085001, Roche) antibodies were used to detect the proteins.

RNA from different cancer cell lines was extracted using RNA isolation kit (Bio Rad) and treated with DNAse using DNAse 1 kit (AMPD1, Sigma-Aldrich). cDNA synthesis was done using cDNA synthesis kit (Bio Rad). qRT-PCR was performed with the primers probing Cdh23 using the real time PCR system (CFX96 Bio Rad).

\section{Cell-aggregation assay}

After 30 hours of post-transfection, the cells were washed gently with PBS and then resuspended in Hank's buffer supplemented with $10 \mathrm{mM} \mathrm{Ca}^{2+}$ ions to a final cell count of $10^{5}$ cells. Hank's 
buffer behaves like an incomplete media maintaining the osmolarity of the solution with the cells avoiding any bursting or shrinking of cells throughout the entire duration of the assay. After resuspending, the cells were imaged with a bright-field filter at 10X magnification using a Leica Inverted Microscope (Leica DMi8) over a time trace for 2 hours. The images were collected at 10 min, 15min, $30 \mathrm{~min}, 45 \mathrm{~min}, 60 \mathrm{~min}$, and $120 \mathrm{~min}$ when all the cells aggregated completely. The image analysis for measuring the area of each aggregate was done in ImageJ software. The aggregates with atleast 5 cells are considered for the analysis. The mean area of aggregates over four different focal positions were measured and plotted against time. The aggregate size was compared over varying domain lengths for $\mathrm{Cdh} 23$. We performed all cell aggregation experiments at fixed cell-types and numbers. $1 \%(\mathrm{w} / \mathrm{v})$ of 1,6-Hexanediol was added in the Hank's buffer for disrupting the LLPS during the cell-aggregation assays.

\section{Fitting the cell aggregation data to a model}

We have used Von Bertalanffy model(West and Newton, 2019, Benzekry et al., 2014) to quantify the rate of cell-cell aggregation for HEK293 cells transfected with Cdh23 EC1-10 and Cdh23 EC127 at different calcium concentrations. The net rate of cell aggregation is proportional to the total area of aggregate. In the absence of any dissociation in our experiment timescale, we have neglected the loss term in the equation (a special case of Von Bertalanffy model). Finally, we fit the cell aggregation data for anexperimental condition over time using the following rate-equation:

$$
\frac{d A}{d t}=a_{o n}^{0} \cdot A^{\gamma}
$$

The model is solved and written explicitly as, $A(t)=\left(a_{o n}^{0} . t .(1-\gamma)\right)^{\frac{1}{1-\gamma}}$, where, $a_{o n}^{0}$ represents the rate-constant, $A$ represents the area of aggregate, $t$ is the independent variable (time), and $\gamma$ represents the growth of aggregate. $a_{o n}^{0}$ is an inherent property and $\gamma$ is dependent on the cell types and their heterogeneity. While fitting, we, therefore, performed global fits and shared the value of $\gamma$ (Table S1).

\section{Live cell imaging and FRAP analysis}

Stably expressing Cdh23 HEK293 cells grown for confluency on a 35mm glass-base petri dish were used for imaging. A super-resolution microscope (Zeiss LSM980 Airyscan 2) was used to image the cells maintained at $37^{\circ} \mathrm{C}$ and $5 \% \mathrm{CO} 2$. FRAP was performed on a confocal volume of $1 \mu \mathrm{m}$ diameter at the cell-cell junctions where localization of eGFP was noticed. ImageJ software was used to measure the fluorescence intensity profiles the line segment of $4 \mu \mathrm{m}$ drawn across the photobleached region (line-scan analysis). The fluorescence intensity profiles (normalized) at different time points were fit to the Gaussian function in origin software. The fitted widths obtained at different time points were plotted against recovery time, and fit to linear regression to estimate the diffusion coefficient from slope (Erami et al., 2016). 


\section{Acknowledgments}

This work was supported by the DBT/Wellcome Trust India Alliance Fellowship [grant number: IA/I/15/1/501817] awarded to S.R.

S.R. acknowledges and thanks Dr. Raj K. Ladher, NCBS for generously donating the Cadherin-23 plasmid. S.R. acknowledges the financial support by the DBT/Wellcome Trust India Alliance, Indian Institute of Science Education and Research Mohali (IISERM), and Centre for Protein Science Design and Engineering (CPSDE), Indian Institute of Science Education and Research Mohali. G.S.S., C.S.S. and A.S. sincerely thank IISERM for financial support. S.D. thanks DBT/Wellcome Trust India Alliance for Project Assistant Fellowship awarded to S.R. A.K is grateful to DST Inspire for funding.

The authors declare no competing financial interests.

\section{Author Contributions}

S.R. has supervised the project. G.S.S., S.D., A.S. and A.K. did the cloning, expression, and purification. G.S.S. and C.S.S. recorded and analysed droplet condensation and cell-aggregation experiments. C.S.S. carried out the curve fitting. C.S.S. did the live-cell imaging and FRAP experiments. G.S.S., and C.S.S. made the figures. S.R. and C.S.S. wrote the manuscript. G.S.S., C.S.S. and S.R. edited the manuscript. C.S.S. and G.S.S. have contributed equally.

\section{References}

AMBADIPUDI, S., BIERNAT, J., RIEDEL, D., MANDELKOW, E. \& ZWECKSTETTER, M. 2017. Liquid-liquid phase separation of the microtubule-binding repeats of the Alzheimer-related protein Tau. Nature Communications, 8, 275.

BANJADE, S. \& ROSEN, M. K. 2014. Phase transitions of multivalent proteins can promote clustering of membrane receptors. Elife, 3.

BELL, G. I. 1978. Models for the specific adhesion of cells to cells. Science, 200, 618-27.

BENZEKRY, S., LAMONT, C., BEHESHTI, A., TRACZ, A., EBOS, J. M., HLATKY, L. \& HAHNFELDT, P. 2014. Classical mathematical models for description and prediction of experimental tumor growth. PLoS Comput Biol, 10, e1003800.

BEUTEL, O., MARASPINI, R., POMBO-GARCIA, K., MARTIN-LEMAITRE, C. \& HONIGMANN, A. 2019. Phase Separation of Zonula Occludens Proteins Drives Formation of Tight Junctions. Cell, 179, 923-936 e11.

BUCHAN, J. R. \& PARKER, R. 2009. Eukaryotic stress granules: the ins and outs of translation. Mol Cell, $36,932-41$.

BUSTAMANTE, C., MARKO, J. F., SIGGIA, E. D. \& SMITH, S. 1994. Entropic elasticity of lambdaphage DNA. Science, 265, 1599-600.

CHOUDHARY, D., NARUI, Y., NEEL, B. L., WIMALASENA, L. N., KLANSECK, C. F., DE-LATORRE, P., CHEN, C., ARAYA-SECCHI, R., TAMILSELVAN, E. \& SOTOMAYOR, M. 2020. Structural determinants of protocadherin-15 mechanics and function in hearing and balance perception. Proc Natl Acad Sci U S A, 117, 24837-24848.

DELARUE, M., BRITTINGHAM, G. P., PFEFFER, S., SUROVTSEV, I. V., PINGLAY, S., KENNEDY, K. J., SCHAFFER, M., GUTIERREZ, J. I., SANG, D., POTEREWICZ, G., CHUNG, J. K., 
PLITZKO, J. M., GROVES, J. T., JACOBS-WAGNER, C., ENGEL, B. D. \& HOLT, L. J. 2018. mTORC1 Controls Phase Separation and the Biophysical Properties of the Cytoplasm by Tuning Crowding. Cell, 174, 338-349 e20.

DI PALMA, F., HOLME, R. H., BRYDA, E. C., BELYANTSEVA, I. A., PELLEGRINO, R., KACHAR, B., STEEL, K. P. \& NOBEN-TRAUTH, K. 2001. Mutations in Cdh23, encoding a new type of cadherin, cause stereocilia disorganization in waltzer, the mouse model for Usher syndrome type 1D. Nat Genet, 27, 103-7.

DIGNON, G. L., BEST, R. B. \& MITTAL, J. 2020. Biomolecular Phase Separation: From Molecular Driving Forces to Macroscopic Properties. Annu Rev Phys Chem, 71, 53-75.

DUSTER, R., KALTHEUNER, I. H., SCHMITZ, M. \& GEYER, M. 2021. 1,6-Hexanediol, commonly used to dissolve liquid-liquid phase separated condensates, directly impairs kinase and phosphatase activities. J Biol Chem, 296, 100260.

ELBAUM-GARFINKLE, S. 2019. Matter over mind: Liquid phase separation and neurodegeneration. J Biol Chem, 294, 7160-7168.

ERAMI, Z., HERRMANN, D., WARREN, S. C., NOBIS, M., MCGHEE, E. J., LUCAS, M. C., LEUNG, W., REISCHMANN, N., MROWINSKA, A., SCHWARZ, J. P., KADIR, S., CONWAY, J. R. W., VENNIN, C., KARIM, S. A., CAMPBELL, A. D., GALLEGO-ORTEGA, D., MAGENAU, A., MURPHY, K. J., RIDGWAY, R. A., LAW, A. M., WALTERS, S. N., GREY, S. T., CROUCHER, D. R., ZHANG, L., HERZOG, H., HARDEMAN, E. C., GUNNING, P. W., ORMANDY, C. J., EVANS, T. R. J., STRATHDEE, D., SANSOM, O. J., MORTON, J. P., ANDERSON, K. I. \& TIMPSON, P. 2016. Intravital FRAP Imaging using an E-cadherin-GFP Mouse Reveals Diseaseand Drug-Dependent Dynamic Regulation of Cell-Cell Junctions in Live Tissue. Cell Rep, 14, 152167.

EVANS, E. \& RITCHIE, K. 1997. Dynamic strength of molecular adhesion bonds. Biophys J, 72, 154155.

GALL, J. G. 2003. The centennial of the Cajal body. Nat Rev Mol Cell Biol, 4, 975-80.

HARRISON, O. J., JIN, X., HONG, S., BAHNA, F., AHLSEN, G., BRASCH, J., WU, Y., VENDOME, J., FELSOVALYI, K., HAMPTON, C. M., TROYANOVSKY, R. B., BEN-SHAUL, A., FRANK, J., TROYANOVSKY, S. M., SHAPIRO, L. \& HONIG, B. 2011. The extracellular architecture of adherens junctions revealed by crystal structures of type I cadherins. Structure, 19, 244-56.

HE, Y., LI, J. \& ZHANG, M. 2019. Myosin VII, USH1C, and ANKS4B or USH1G Together Form Condensed Molecular Assembly via Liquid-Liquid Phase Separation. Cell Rep, 29, 974-986 e4.

HIRANO, S. 2012. Western blot analysis. Methods Mol Biol, 926, 87-97.

INDZHYKULIAN, A. A., STEPANYAN, R., NELINA, A., SPINELLI, K. J., AHMED, Z. M., BELYANTSEVA, I. A., FRIEDMAN, T. B., BARR-GILLESPIE, P. G. \& FROLENKOV, G. I. 2013. Molecular remodeling of tip links underlies mechanosensory regeneration in auditory hair cells. PLoS Biol, 11, e1001583.

ITOH, Y., IIDA, S., TAMURA, S., NAGASHIMA, R., SHIRAKI, K., GOTO, T., HIBINO, K., IDE, S. \& MAESHIMA, K. 2021. 1,6-hexanediol rapidly immobilizes and condenses chromatin in living human cells. Life Sci Alliance, 4.

JAIGANESH, A., DE-LA-TORRE, P., PATEL, A. A., TERMINE, D. J., VELEZ-CORTES, F., CHEN, C. \& SOTOMAYOR, M. 2018. Zooming in on Cadherin-23: Structural Diversity and Potential Mechanisms of Inherited Deafness. Structure, 26, 1210-1225 e4.

KACHAR, B., PARAKKAL, M., KURC, M., ZHAO, Y. \& GILLESPIE, P. G. 2000. High-resolution structure of hair-cell tip links. Proc Natl Acad Sci U S A, 97, 13336-41.

KANAAN, N. M., HAMEL, C., GRABINSKI, T. \& COMBS, B. 2020. Liquid-liquid phase separation induces pathogenic tau conformations in vitro. Nat Commun, 11, 2809.

KAUR, T., AlShAREEDAH, I., WANG, W., NGO, J., MOOSA, M. M. \& BANERJEE, P. R. 2019. Molecular Crowding Tunes Material States of Ribonucleoprotein Condensates. Biomolecules, 9. 
KLUS, P., BOlOGNESI, B., AGOSTINI, F., MARCHESE, D., ZANZONI, A. \& TARTAGLIA, G. G. 2014. The cleverSuite approach for protein characterization: predictions of structural properties, solubility, chaperone requirements and RNA-binding abilities. Bioinformatics, 30, 1601-8.

KUHNER, F., COSTA, L. T., BISCH, P. M., THALHAMMER, S., HECKL, W. M. \& GAUB, H. E. 2004. LexA-DNA bond strength by single molecule force spectroscopy. Biophys J, 87, 2683-90.

KUMAR, A., RIZVI, M. S., ATHILINGAM, T., PARIHAR, S. S. \& SINHA, P. 2020. Heterophilic cellcell adhesion of atypical cadherins Fat and Dachsous regulate epithelial cell size dynamics during Drosophila thorax morphogenesis. Mol Biol Cell, 31, 546-560.

LATONEN, L. 2019. Phase-to-Phase With Nucleoli - Stress Responses, Protein Aggregation and Novel Roles of RNA. Front Cell Neurosci, 13, 151.

LI, Q., CHENG, Z., ZHOU, L., DARMANIS, S., NEFF, N. F., OKAMOTO, J., GULATI, G., BENNETT, M. L., SUN, L. O., CLARKE, L. E., MARSCHALLINGER, J., YU, G., QUAKE, S. R., WYSSCORAY, T. \& BARRES, B. A. 2019. Developmental Heterogeneity of Microglia and Brain Myeloid Cells Revealed by Deep Single-Cell RNA Sequencing. Neuron, 101, 207-223 e10.

MAHEN, R. \& VENKITARAMAN, A. R. 2012. Pattern formation in centrosome assembly. Curr Opin Cell Biol, 24, 14-23.

MCNEIL, E., CAPALDO, C. T. \& MACARA, I. G. 2006. Zonula occludens-1 function in the assembly of tight junctions in Madin-Darby canine kidney epithelial cells. Mol Biol Cell, 17, 1922-32.

MITCHELL, S. F., JAIN, S., SHE, M. \& PARKER, R. 2013. Global analysis of yeast mRNPs. Nat Struct Mol Biol, 20, 127-33.

MUlHALL, E. M., WARD, A., YANG, D., KOUSSA, M. A., COREY, D. P. \& WONG, W. P. 2021. Single-molecule force spectroscopy reveals the dynamic strength of the hair-cell tip-link connection. Nat Commun, 12, 849.

NARUI, Y. \& SOTOMAYOR, M. 2018. Tuning Inner-Ear Tip-Link Affinity Through Alternatively Spliced Variants of Protocadherin-15. Biochemistry, 57, 1702-1710.

PATEL, A., MALINOVSKA, L., SAHA, S., WANG, J., ALBERTI, S., KRISHNAN, Y. \& HYMAN, A. A. 2017. ATP as a biological hydrotrope. Science, 356, 753-756.

PINCET, F., ADRIEN, V., YANG, R., DELACOTTE, J., ROTHMAN, J. E., URBACH, W. \& TARESTE, D. 2016. FRAP to Characterize Molecular Diffusion and Interaction in Various Membrane Environments. PLoS One, 11, e0158457.

POCZOBUTT, J. M., DE, S., YADAV, V. K., NGUYEN, T. T., LI, H., SIPPEL, T. R., WEISER-EVANS, M. C. \& NEMENOFF, R. A. 2016. Expression Profiling of Macrophages Reveals Multiple Populations with Distinct Biological Roles in an Immunocompetent Orthotopic Model of Lung Cancer. J Immunol, 196, 2847-59.

PONTANI, L. L., JORJADZE, I. \& BRUJIC, J. 2016. Cis and Trans Cooperativity of E-Cadherin Mediates Adhesion in Biomimetic Lipid Droplets. Biophys J, 110, 391-399.

RAY, C., BROWN, J. R. \& AKHREMITCHEV, B. B. 2007. Rupture force analysis and the associated systematic errors in force spectroscopy by AFM. Langmuir, 23, 6076-83.

SANNIGRAHI, M. K., SRINIVAS, C. S., DEOKATE, N. \& RAKSHIT, S. 2019. The strong propensity of Cadherin-23 for aggregation inhibits cell migration. Mol Oncol, 13, 1092-1109.

SINGARAJU, G. S., SAGAR, A., KUMAR, A., SAMUEL, J. S., HAZRA, J. P., SANNIGRAHI, M. K., YENNAMALLI, R. M., ASHISH, F. \& RAKSHIT, S. 2019. Structural basis of the strong cell-cell junction formed by cadherin-23. FEBS J.

SOTOMAYOR, M., WEIHOFEN, W. A., GAUDET, R. \& COREY, D. P. 2010. Structural determinants of cadherin-23 function in hearing and deafness. Neuron, 66, 85-100.

SOTOMAYOR, M., WEIHOFEN, W. A., GAUDET, R. \& COREY, D. P. 2012. Structure of a forceconveying cadherin bond essential for inner-ear mechanotransduction. Nature, 492, 128-32.

SRINIVASAN, S., HAZRA, J. P., SINGARAJU, G. S., DEB, D. \& RAKSHIT, S. 2017. ESCORTing proteins directly from whole cell-lysate for single-molecule studies. Anal Biochem, 535, 35-42.

THOMPSON, C. J., SU, Z., VU, V. H., WU, Y., LECKBAND, D. E. \& SCHWARTZ, D. K. 2020. Cadherin clusters stabilized by a combination of specific and nonspecific cis-interactions. Elife, 9. 
THOMPSON, C. J., VU, V. H., LECKBAND, D. E. \& SCHWARTZ, D. K. 2019. Cadherin Extracellular Domain Clustering in the Absence of Trans-Interactions. J Phys Chem Lett, 10, 4528-4534.

WANG, Z., ZHANG, G. \& ZHANG, H. 2019. Protocol for analyzing protein liquid-liquid phase separation. Biophysics Reports, 5, 1-9.

WEST, J. \& NEWTON, P. K. 2019. Cellular interactions constrain tumor growth. Proc Natl Acad Sci U S A, 116, 1918-1923.

WU, Y., JIN, X., HARRISON, O., SHAPIRO, L., HONIG, B. H. \& BEN-SHAUL, A. 2010. Cooperativity between trans and cis interactions in cadherin-mediated junction formation. Proc Natl Acad Sci U S A, 107, 17592-7.

WU, Y., KANCHANAWONG, P. \& ZAIDEL-BAR, R. 2015. Actin-delimited adhesion-independent clustering of E-cadherin forms the nanoscale building blocks of adherens junctions. Dev Cell, 32, 139-54.

ZHANG, Y., CHEN, K., SLOAN, S. A., BENNETT, M. L., SCHOLZE, A. R., O'KEEFFE, S., PHATNANI, H. P., GUARNIERI, P., CANEDA, C., RUDERISCH, N., DENG, S., LIDDELOW, S. A., ZHANG, C., DANEMAN, R., MANIATIS, T., BARRES, B. A. \& WU, J. Q. 2014. An RNA-sequencing transcriptome and splicing database of glia, neurons, and vascular cells of the cerebral cortex. J Neurosci, 34, 11929-47.

ZHANG, Y., SLOAN, S. A., ClARKE, L. E., CANEDA, C., PlAZA, C. A., BLUMENTHAL, P. D., VOGEL, H., STEINBERG, G. K., EDWARDS, M. S., LI, G., DUNCAN, J. A., 3RD, CHESHIER, S. H., SHUER, L. M., CHANG, E. F., GRANT, G. A., GEPHART, M. G. \& BARRES, B. A. 2016. Purification and Characterization of Progenitor and Mature Human Astrocytes Reveals Transcriptional and Functional Differences with Mouse. Neuron, 89, 37-53. 


\section{Abbreviations}

AUC Analytical UltraCentrifugation

Cdh23 Cadherin-23

CDF Cumulative Distribution Function

CD Cytosolic domain

DAPI 4,6-diamidino-2-phenylindole

EC Extracellular

EC1-10 Extracellular 1-10 domains

EC1-27 Extracellular 1-27 domains

eGFP Enhanced Green fluorescent protein

FRAP Fluorescence Recovery After Photobleaching

1,6-HD 1,6-Hexanediol

ITC Isothermal titration calorimetry

LLPS Liquid- Liquid Phase Separation

Pcdh15 Protocadherin-15

qRT-PCR Quantitative Real-time polymerase chain reaction

SPR Surface Plamon Resonance

TM Transmembrane 

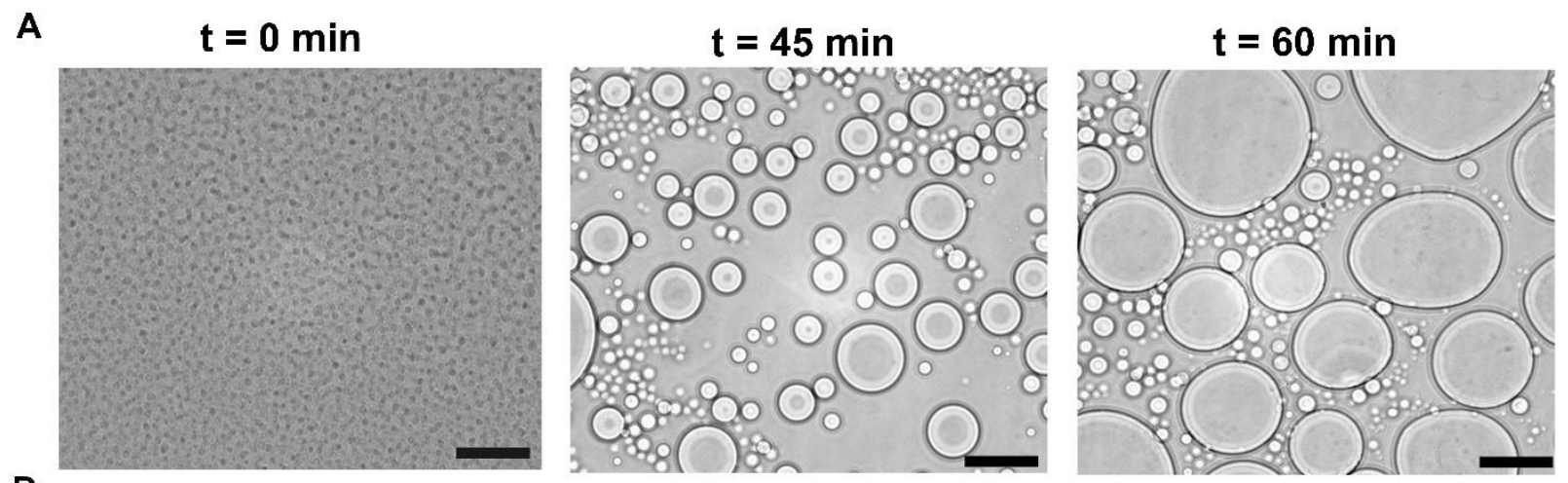

B
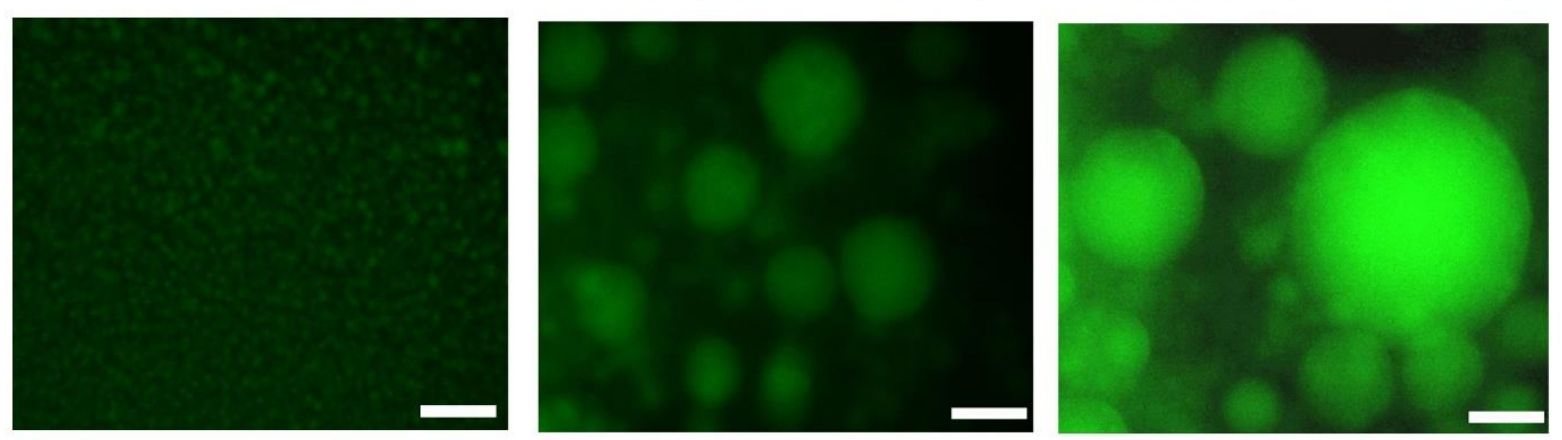

C

D
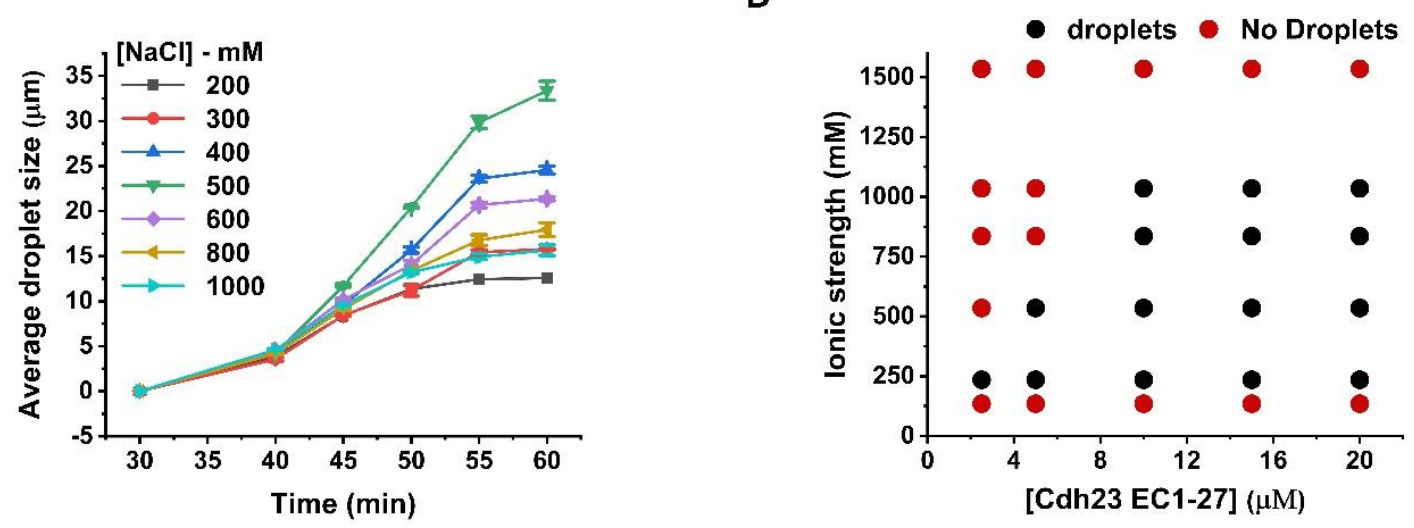

Figure 1. LLPS of Cadherin-23. (A) Representative bright-field images, and (B) fluorescence images of liquid droplet-like condensates of Cdh23 EC1-27 at three different time intervals (i) 0 min, (ii) $45 \mathrm{~min}$, and (iii) $60 \mathrm{~min}$. Buffer composition is $20 \mathrm{mM}$ HEPES, $500 \mathrm{mM} \mathrm{NaCl}$ and $6 \mathrm{mM} \mathrm{CaCl}_{2}$. Scale bar: $50 \mu \mathrm{m}$. (C) Growth kinetics of liquid droplets $(\mu \mathrm{m})$ at a varying concentration of $\mathrm{NaCl}$. Error bars represent the standard error of the mean (SEM) with N=30 droplets. (D) Phase diagram of liquid droplets of Cdh23 EC1-27 relating protein concentration and ionic strength of the buffer with droplet formation. 
A
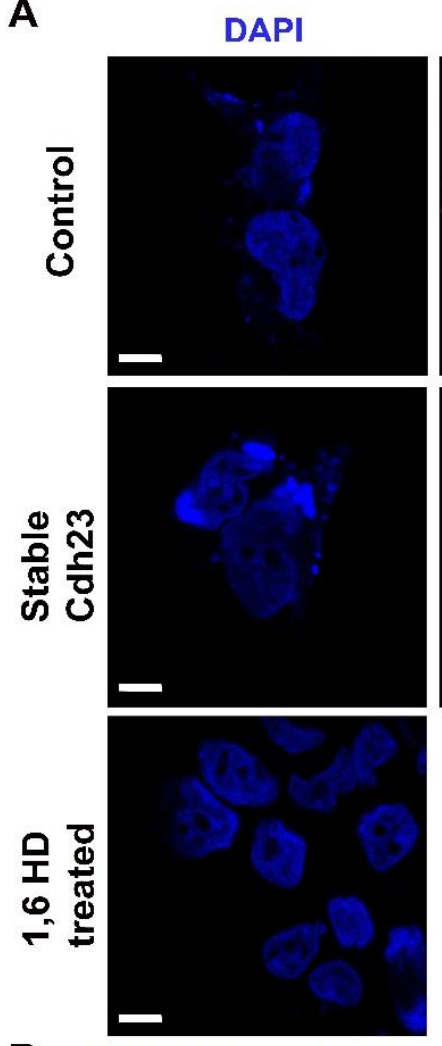

B

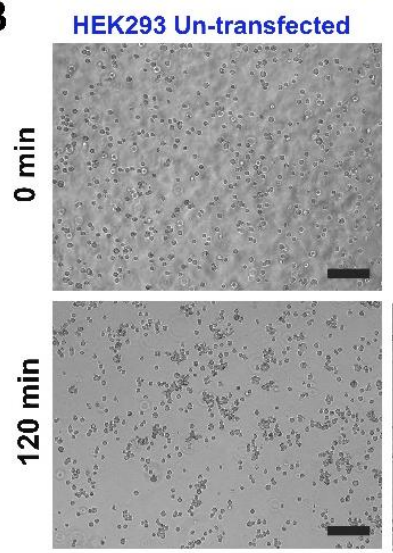

C

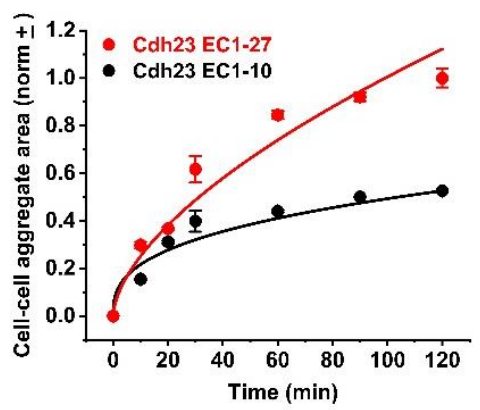

Cdh23
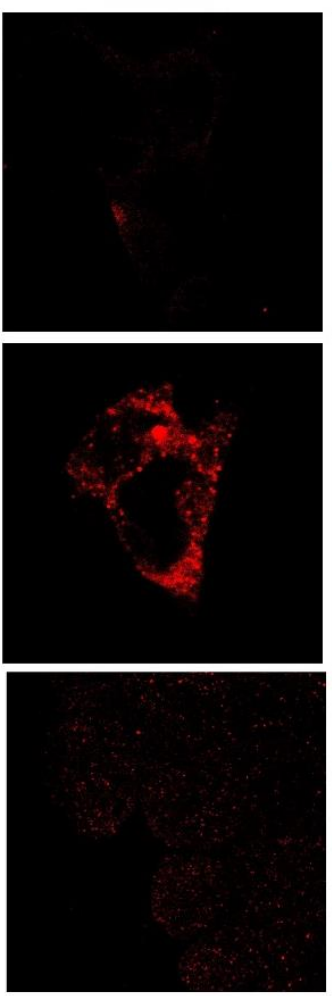

HEK293 Cdh23 EC1-10
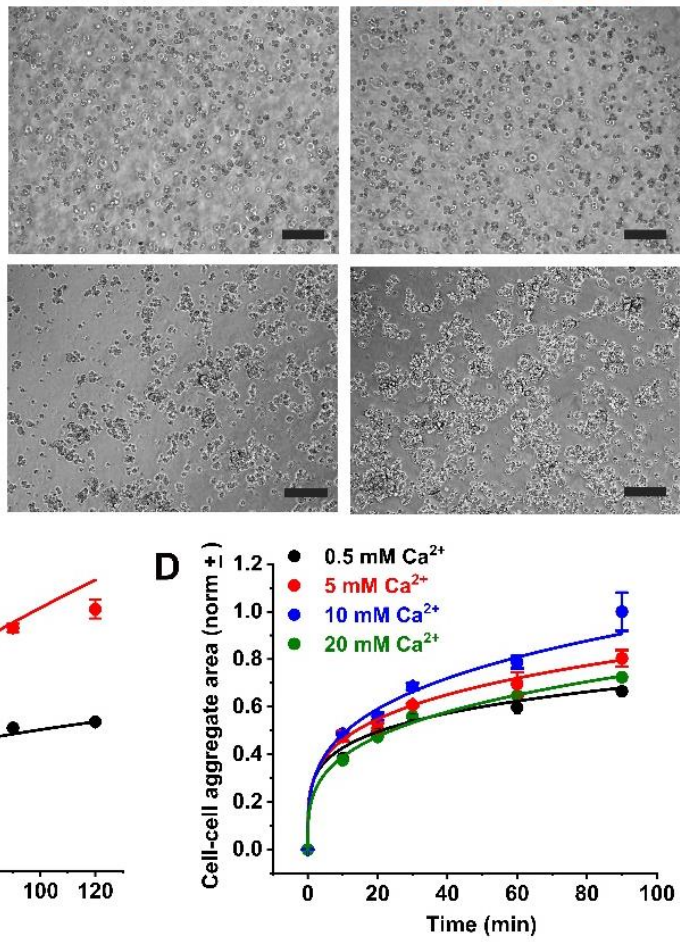

Figure 2. LLPS of Cdh23 facilitates cell-cell adhesion. (A) The immunofluorescence images of the puncta (red)of Cdh23 on HEK293 cells exogenously expressing Cdh23 (Middle row). No puncta were 
noticed in control (top row). Bottom row: Disruption of puncta after 1,6-Hexanediol (1,6-HD) treatment to HEK293 cells exogenously expressing Cdh23. DAPI is to stain the nucleus (blue). Scale bar: $10 \mu \mathrm{m}$. (B) Time-stamp bright-field images of cell-cell aggregations of HEK293 cells untransfected ( $1^{\text {st }}$ column), transiently transfected with Cdh23 EC1-10 ( $2^{\text {nd }}$ column), and Cdh23 EC1-27 ( $3^{\text {rd }}$ column). Scale bar: 50 $\mu \mathrm{m}$. (C) The time-dependent growth of the cell-cell aggregation area (normalized) of HEK293 cells exogenously expressing Cdh23 EC1-27 (red) and Cdh23 EC1-10 (black), along with the Von Bertalanffy model fit (solid lines). The error bars represent the standard error of the mean (SEM) with $\mathrm{N}=15$ aggregates. (D) The time-dependent growth of the cell-cell aggregation area (normalized) of HEK293 cells exogenously expressing Cdh23 EC1-27 at varying calcium concentrations. The error bars represent the standard error of the mean (SEM) for $\mathrm{N}=15$ aggregates. The solid lines represent the fitting of aggregation kinetics to the Von Bertalanffy model. 

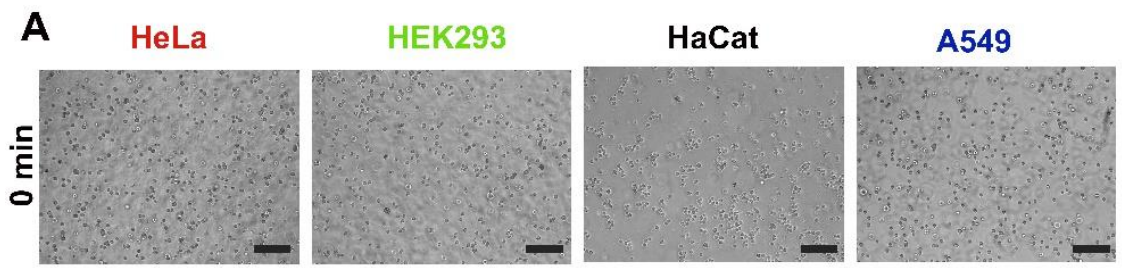

\section{B}
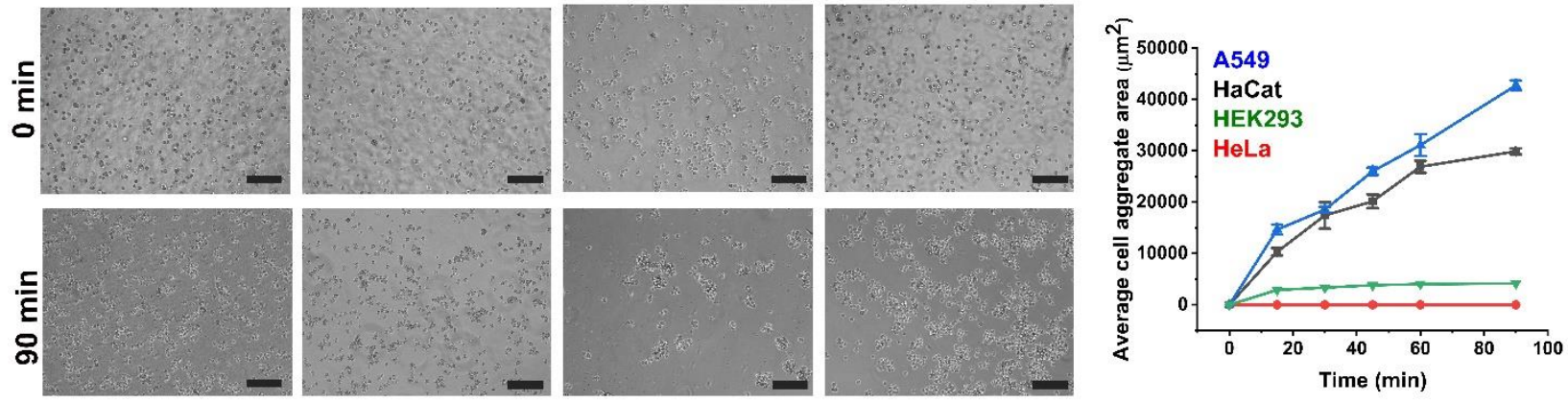

Figure 3. Dependence of cell-cell adhesion rate on the intrinsic expression of Cdh23. (A) Time-stamp bright-field images of cell-aggregates of HeLa, HEK293, HaCat, and A549 cells differentially expressing endogenous Cdh23. Scale bar: $50 \mu \mathrm{m}$. (B) Growth of cell-cell aggregation area (in $\left.\mu \mathrm{m}^{2}\right)$ with time for HeLa (red), HEK293 (green), HaCat. (black) and A549 (blue) cell lines. Error bars represent the standard error of the mean (SEM) for $\mathrm{N}=15$ aggregates. 


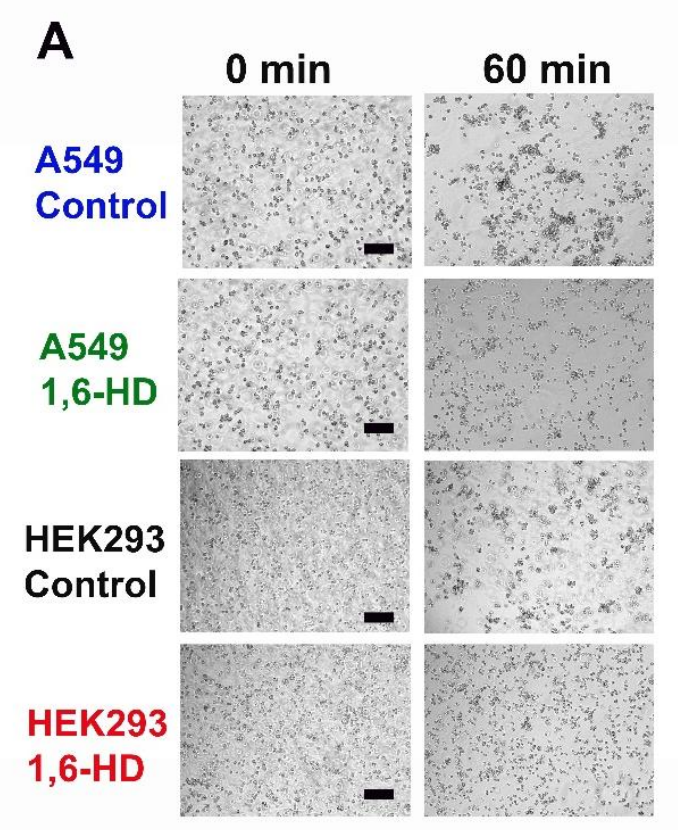

\section{B}

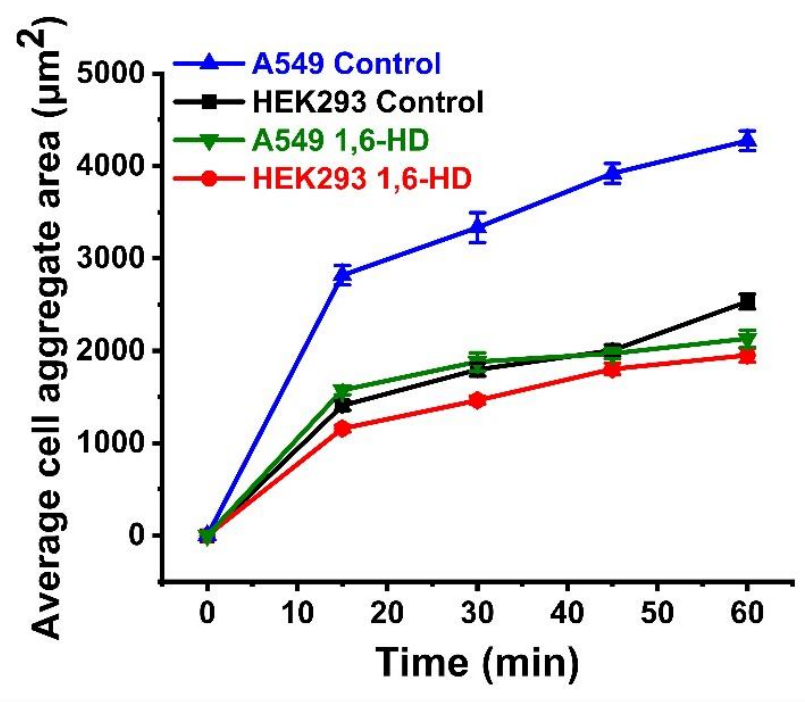

Figure 4. Effect of disrupted cis-clusters on cell-adhesion kinetics. (A) Time-stamp bright-field images of cell aggregates of A549 and HEK293 cells in absence (control) and presence of 1,6-HD. Scale bar: $50 \mu \mathrm{m}$. (B) Growth of cell-cell aggregation area (in $\mu \mathrm{m}^{2}$ ) with time for A549 cells in Control (blue) and treated with 1,6-HD (Olive), and HEK2923 cells in control (black) and treated with 1,6-HD (red). Error bars represent the standard error of the mean (SEM) for $\mathrm{N}=15$ aggregates. 
A

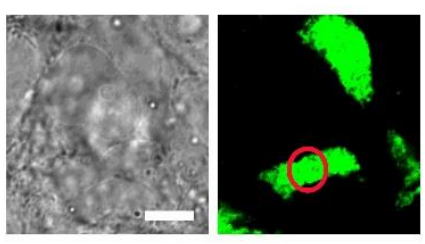

B

C

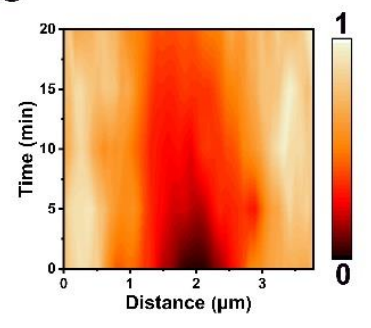

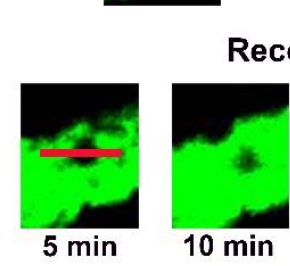

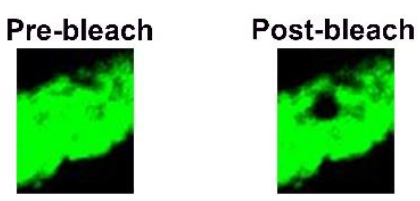

Recovery

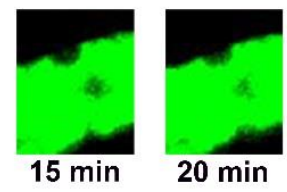

E
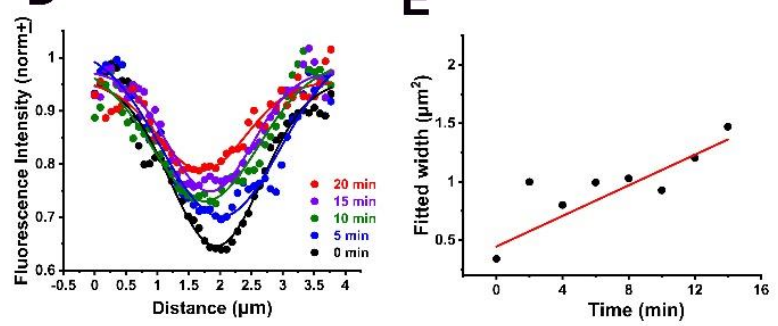

Figure 5. FRAP to probe the fluidic cis-clusters of $\mathrm{Cdh} 23$ at the cell-cell junctions. (A) Representative bright field and fluorescence images show the localization of $\mathrm{Cdh} 23$ at the cell-cell junction of HEK293 cells exogenously expressing Cdh23. Cdh23 is recombinantly tagged with eGFP at C-terminus. The circle (red) indicates the confocal volume for the FRAP experiment. Scale bar: $10 \mu \mathrm{m}$. (B) The cross-sections of fluorescence images indicate the regions of pre-bleach, bleach, and post-bleach recovery at the selected time points. The fluorescence recovery is monitored with time along the red line. The length of the line is $4 \mu \mathrm{m}$. (C) The contour plot represents the spatiotemporal distribution of Cdh23-eGFP along the red line. (D) The fluorescence intensity profile along the red line is plotted with the recovery time points. The solid lines are the Gaussian fits. (E) The widths $\left(\sigma^{2}\right)$ from the Gaussian fits are plotted with recovery time. The solid red line is the linear fit to the data to estimate the diffusion-coefficient. Error bars indicate the standard deviation obtained from the Gaussian fit. 
Table1. Binding-affinities of the heterophilic and homophilic trans-complexes of Cdh23 as reported.

\begin{tabular}{|c|c|c|c|c|c|}
\hline $\begin{array}{c}\text { Homo/Heterophilic } \\
\text { dimer }\end{array}$ & $\begin{array}{c}\text { Interaction } \\
\text { geometry }\end{array}$ & Method & $\mathbf{T}\left({ }^{\mathbf{0}} \mathbf{C}\right)$ & $\boldsymbol{K}_{\boldsymbol{D}}(\boldsymbol{\mu M})$ & Reference \\
\hline $\begin{array}{c}\text { Cdh23 (EC1-2)- } \\
\text { Pcdh15 (EC1-2) }\end{array}$ & Trans & ITC & 10 & $2.9 \pm 0.4$ & Nature, 2012 \\
\hline $\begin{array}{c}\text { Cdh23 (EC1-2)- } \\
\text { Pcdh15 (EC1-2) }\end{array}$ & Trans & SPR & 25 & $0.84 \pm 0.03$ & Biochemistry,2018 \\
\hline $\begin{array}{c}\text { Cdh23 (EC1-2)- } \\
\text { Cdh23 (EC1-2) }\end{array}$ & Trans & AUC & 20 & $18 \pm 4$ & FEBS, J.,2019 \\
\hline
\end{tabular}

$K_{D}$ denotes the dissociation constant

Table2. CDF scores for different cadherins (EC-domains only) estimated using catGRANULE algorithm.

\begin{tabular}{|c|c|}
\hline Cadherins & CDF score \\
\hline$C d h 23$ & 1.259 \\
\hline$P c d h 1$ & 1.002 \\
\hline$D c s h 1$ & 1.350 \\
\hline$F A T 1$ & 1.432 \\
\hline FAT2 & 1.326 \\
\hline FAT3 & 1.538 \\
\hline FAT4 & 1.642 \\
\hline
\end{tabular}

CDF score represents the propensity for LLPS 


\section{Supplementary information for}

\section{Cis-clustering of cadherin-23 controls the kinetics of cell-cell adhesion}

Cheerneni Sai Srinivas ${ }^{1 \#, ~ G a y a t h r i ~ S i n d h u r i ~ S i n g a r a j u " ~}{ }^{\#}$, Sayan Das, Amin Sagar1, Anuj Kumar $^{2}$, and Sabyasachi Rakshit ${ }^{1,3 *}$

*Correspondence to Sabyasachi Rakshit: srakshit@iisermohali.ac.in

${ }^{\#}$ Equal contributions

This file includes:

Figures S1 to S9

Legends for videos $1 \mathrm{~A}$ and $\mathrm{B}$

Table S1 


\section{Supplimentary Figures:}

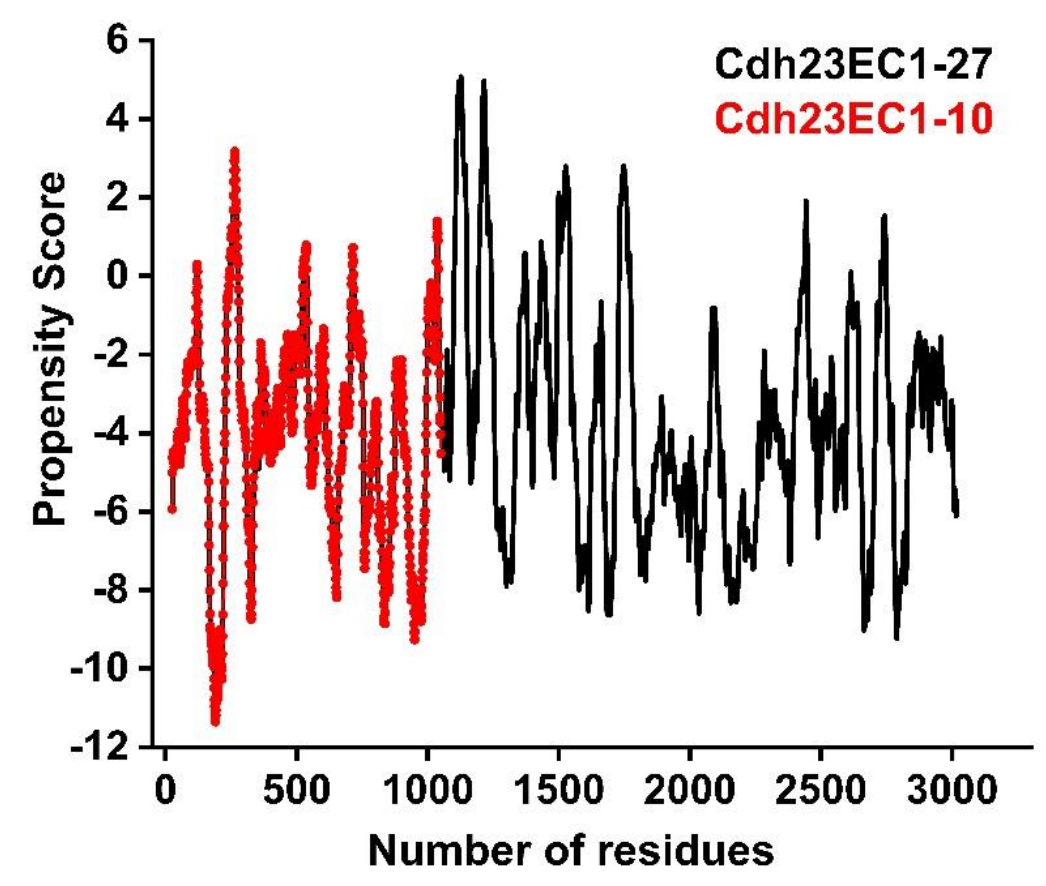

Figure S1. The high propensity of Cdh23 EC1-27 to undergo liquid-liquid phase-separation than Cdh23 EC1-10. The plot of the propensity scores estimated using catGRANULE algorithm for Cdh23 EC1-27 (black) and Cdh23 EC1-10 (red) versus the number of residues shows that a higher number of EC domains is having a higher probability of undergoing LLPS. Propensity scores for Cdh23 EC1-27 and Cdh23 EC1-10 are 1.2932 and 0.8012, respectively. 

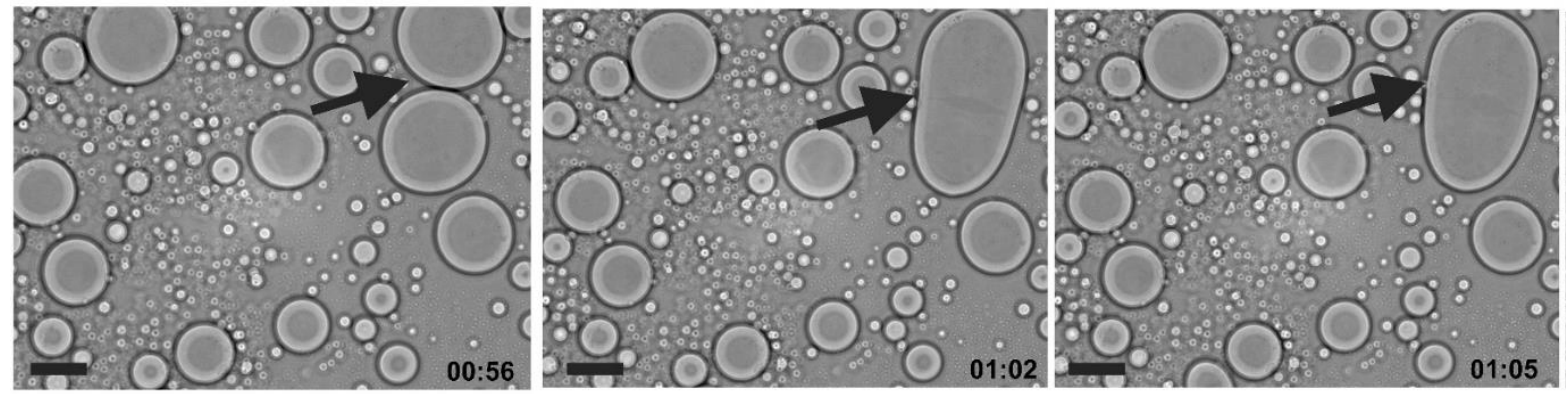

Figure S2. Time-lapse images of droplet fusion (Supporting to Fig. 1, A and B). The bright-field images with time capture one of the fusion events of liquid droplets of Cdh23 EC1-27. Arrows in black are highlighting the droplets undergoing fusion. Scale bar: $50 \mu \mathrm{m}$. 
A

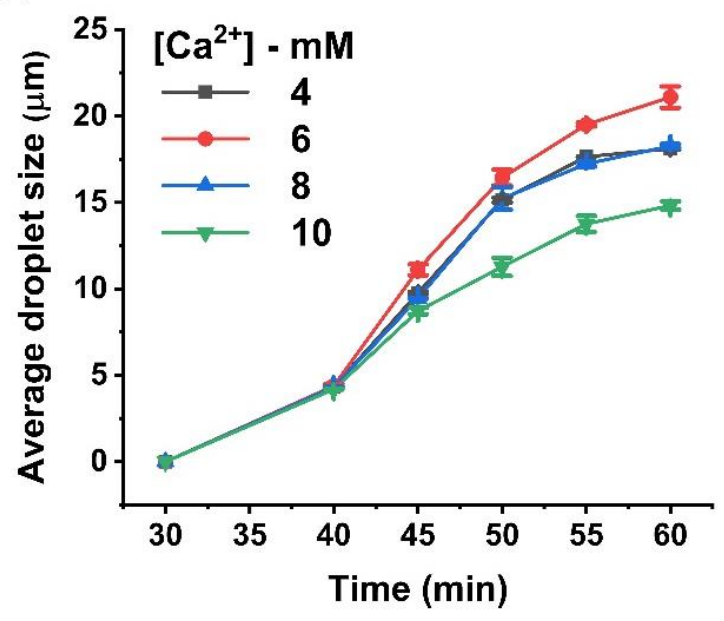

B

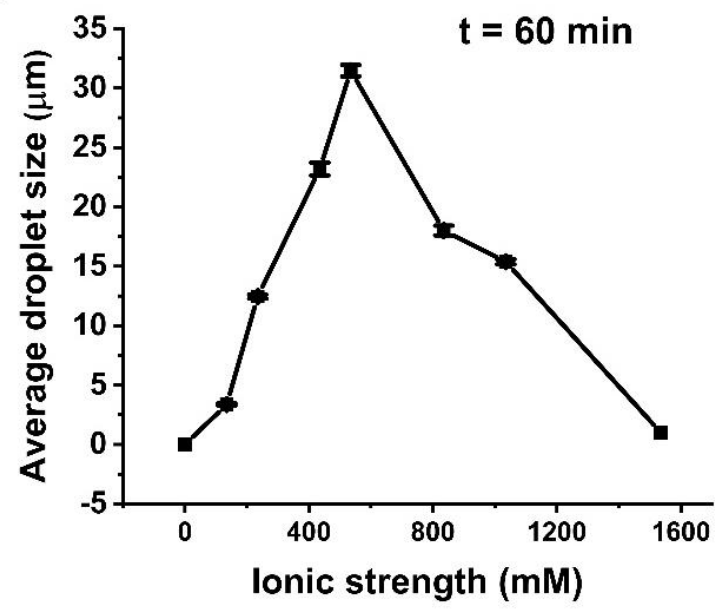

Figure S3. Systematic alterations of $\mathrm{Ca}^{2+}$ ions for the optimization of LLPS of Cdh23 EC127 (Supporting to Fig. 1, C, D). (A) The growth of liquid droplets $(\mu \mathrm{m})$ of Cdh23 EC1-27 with time depends on $\mathrm{Ca}^{2+}$ concentration. Error bars represent the standard error of the mean (SEM) for $\mathrm{N}=30$ droplets. (B) The liquid droplet size of Cdh23 EC1-27 measured after 60 min of nucleation follows a typical bell-shaped curve with increasing ionic strength of the buffer. Error bars represent SEM with $\mathrm{N}=30$ droplets. 


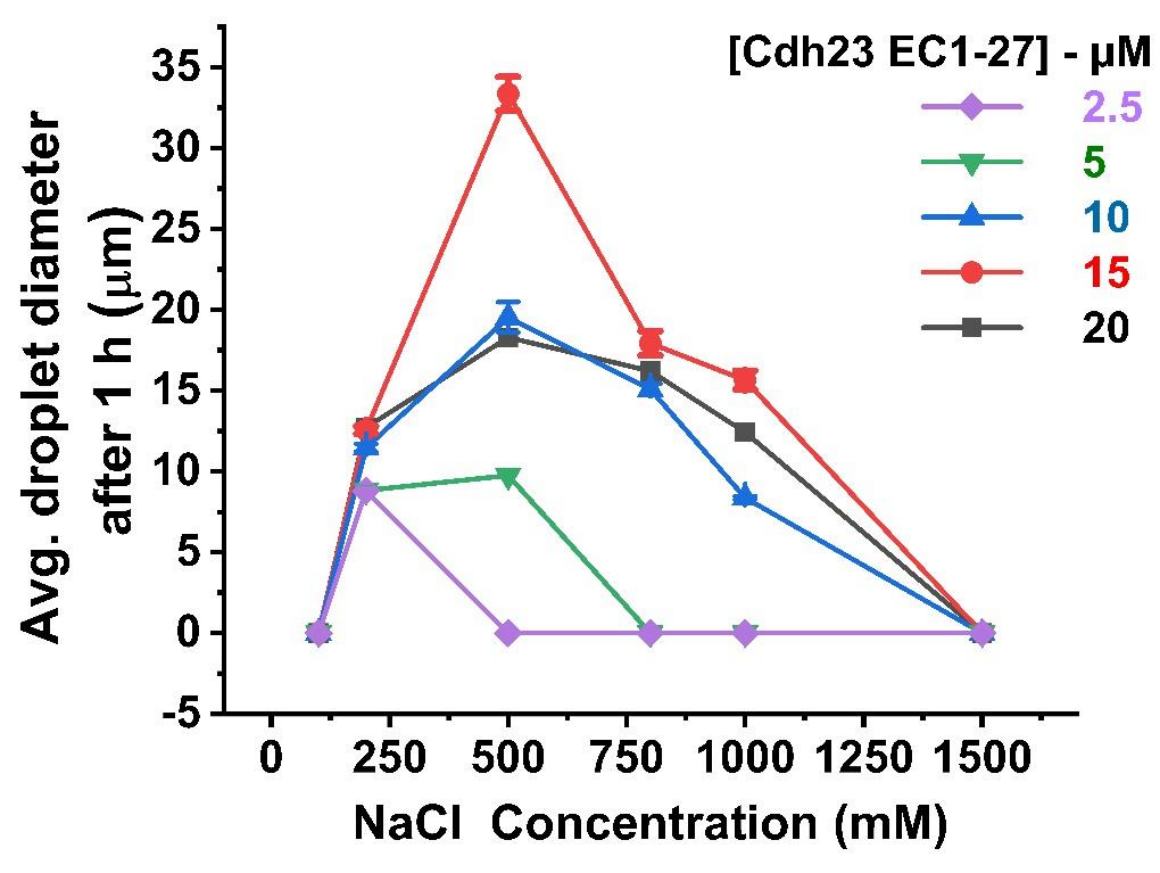

Figure S4. Optimization of LLPS of Cdh23 EC1-27 at varying $\mathrm{NaCl}$ and protein concentrations (Supporting to Fig. 1 D). Error bars represent SEM with N=30 droplets. 

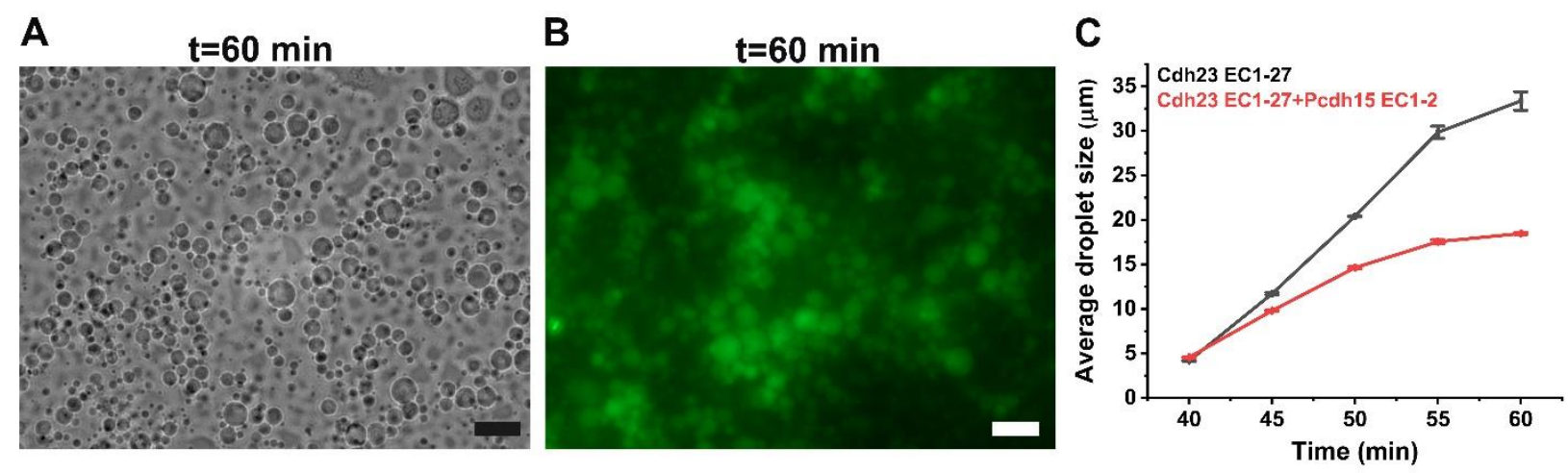

Figure S5. LLPS of Cdh23 EC1-27 in the absence of trans-interactions. (A) Bright-field and (B) fluorescence images of liquid droplets of Cdh23 EC1-27 induced by exclusive cis-interactions. The trans-interactions were turned off by introducing Pcdh15 EC1-2 in the buffer. The scale bar is $50 \mu \mathrm{m}$. (C) The comparative growth kinetics of liquid droplets $(\mu \mathrm{m})$ of Cdh23 EC1-27 in the absence (black) and presence (red) of Pcdh15 EC1-2. Pcdh15 blocks the homophilic trans-binding interface of $\mathrm{Cdh} 23$. 

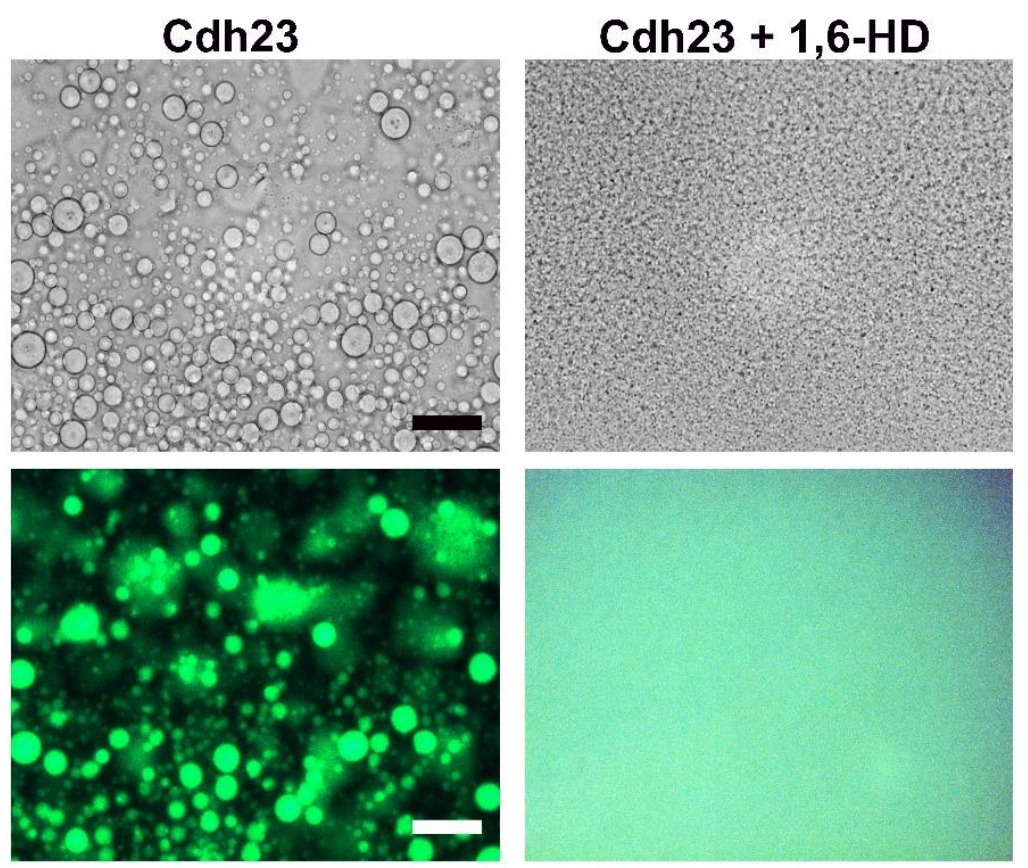

Figure S6. Cis-clustering of Cdh23 drives the LLPS of Cdh23. (A) The representative brightfield and fluorescence images of liquid droplets of Cdh23 EC1-27 in absence (column 1) and presence (column 2) of 1,6-HD. 1,6-HD disrupted the liquid droplets of Cdh23 EC1-27. Scale bar: $50 \mu \mathrm{m}$. 
A

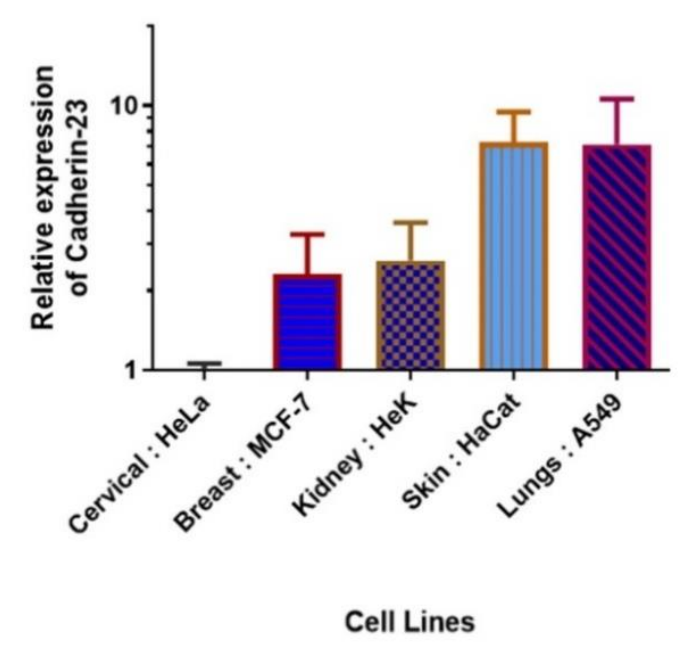

B

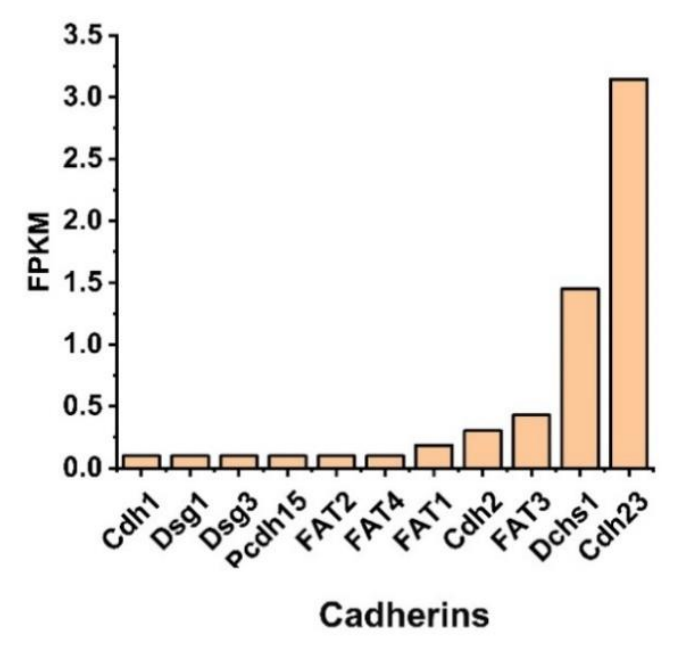

Figure S7. Differential expression of $\mathrm{Cdh} 23$ in cancer cell lines and microglia (Supporting to Fig. 3). (A) The relative expression of Cdh 23 mRNA in different cancer cell lines, namely HeLa, MCF-7, HEK293, HaCat, and A549, quantified using qRT-PCR. The highest expression is noticed in A549 and the most negligible expression in HeLa. (B) Bar plot to display the mRNA expression of different cadherin proteins in microglia cells. FPKM is Fragments Per Kilobase Million essentially represents normalized expression values. 


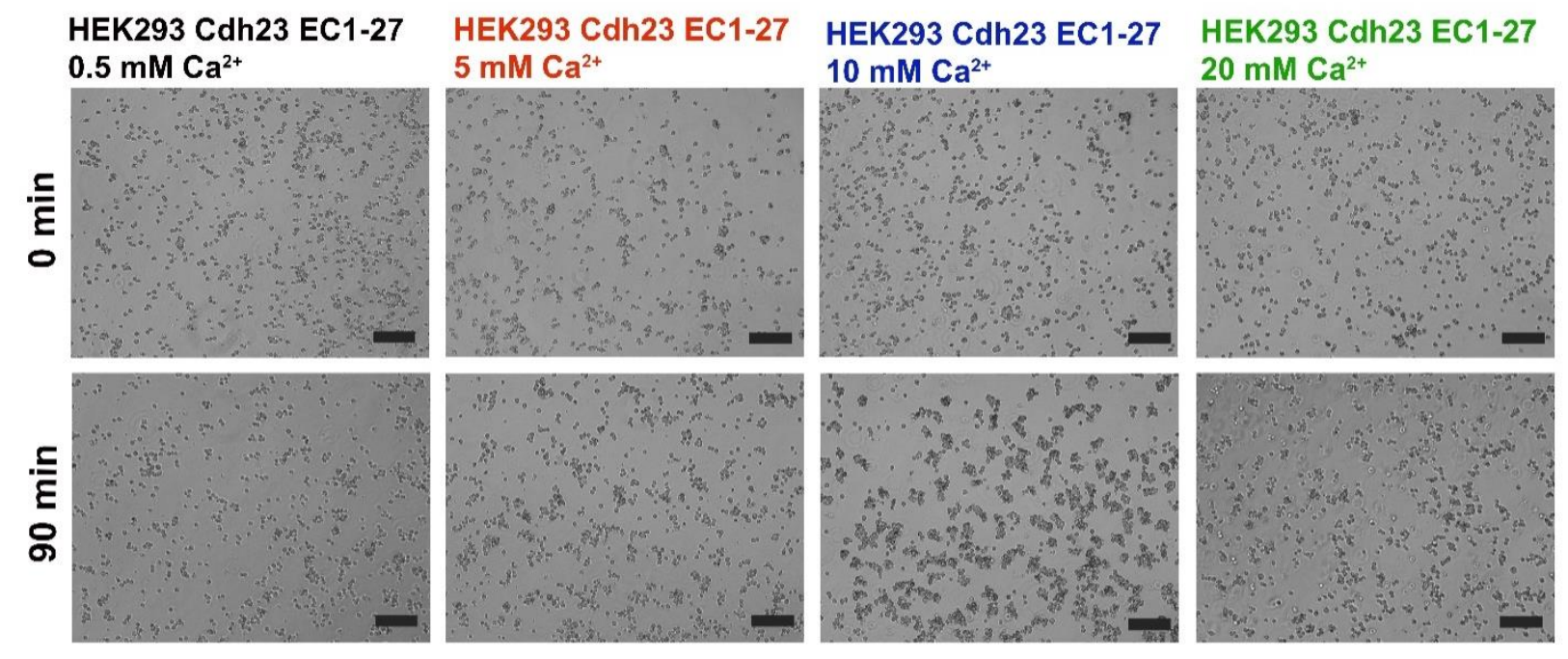

Figure S8. Calcium-dependent cell-cell aggregation of HEK293 cells exogenously expressing Cdh23 (Supporting to Fig. 2 D). Scale bar: $50 \mu \mathrm{m}$ 


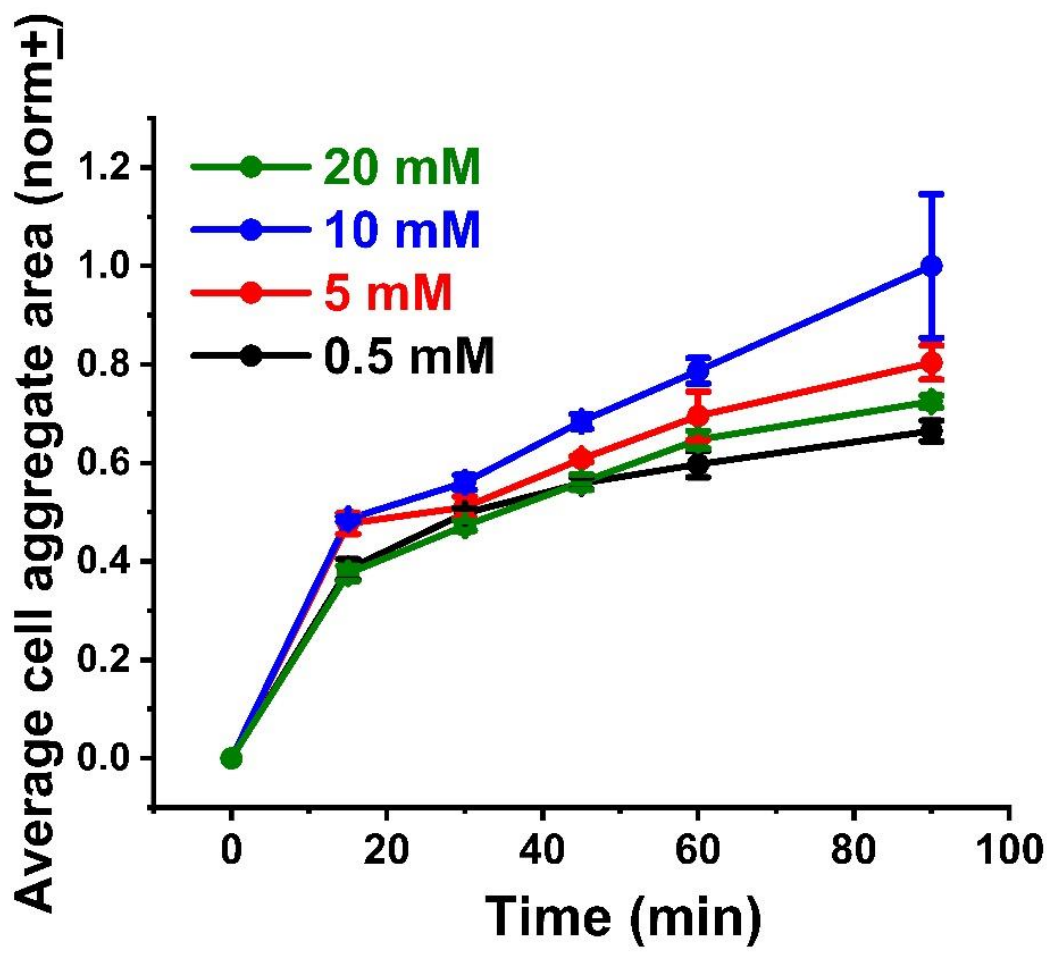

Figure S9. Calcium-dependent cell-cell aggregation of HEK293 cells exogenously expressing Cdh23 (Supporting to Fig. 2 D). The time-dependent growth of the cell-cell aggregation area (normalized) of HEK293 cells exogenously expressing Cdh23 EC1-27 at varying calcium concentrations. The error bars represent the standard error of the mean (SEM) for $\mathrm{N}=15$ aggregates. 
Video 1 A. Fusion of droplets of Cdh23 EC1-27 (Supporting to Fig. 1 F). The fusion of liquid droplets of Cdh23 EC1-27 captured under a fluorescence (GFP) microscope.

Video 1 B. Fusion of droplets of Cdh23 EC1-27 (Supporting to Fig. 1 E). The fusion of liquid droplets of Cdh23 EC1-27 captured under bright-field.

Table S1. The value of $\gamma$ obtained from the fitting of the cell aggregation kinetics to Von Bertalanffy model.

\begin{tabular}{|c|c|}
\hline Cell aggregation experiment & \multirow{2}{*}{$\boldsymbol{\gamma}$} \\
\cline { 1 - 1 } Cdh23 EC1-10 and Cdh23 EC1-27 & \multirow{2}{*}{-2.25} \\
\cline { 1 - 1 } Cdh23 EC1-27 at different $\mathrm{Ca}^{2+}$ concentrations & \\
\hline
\end{tabular}

$\gamma$ represents the growth of the aggregate. 